\title{
Low-Temperature, Vacuum- Aided Thermal Desorption Studies on a Simulated Organic Sludge Waste
}

$R$ K. Farnsworth

D. R. Peterman

G. L. Anderson

T G. Garn

December 2002

Idaho National Engineering and Environmental Laboratory Bechtel BWXT Idaho, LLC 


\title{
Low-Temperature, Vacuum-Aided Thermal Desorption Studies on a Simulated Organic Sludge Waste
}

\author{
R. K. Farnsworth \\ D. R. Peterman \\ G. L. Anderson \\ T. G. Garn
}

December 2002

Idaho National Engineering and Environmental Laboratory

Idaho Falls, Idaho 83415

Prepared for the

U.S. Department of Energy

Assistant Secretary for Environmental Management

Under DOE Idaho Operations Office

Contract DE-AC07-99ID13727 


\begin{abstract}
This report describes an initial set of small scale lab tests conducted on surrogate waste materials to investigate mass release behavior of volatile organics (VOC's) from a solidified liquid organic sludge matrix under vacuumaided, low-temperature thermal desorption conditions. Low temperature thermal desorption is being considered as a potential processing technology alternative to incineration, to remove gas generation limitations affecting the transportation of transuranic (TRU) contaminated organic sludge wastes to a designated off-site repository (i.e., the Waste Isolation Pilot Plant). The lab-scale tests provide initial exploratory level information on temperature profiles and rates of volatile organic desorption for a range of initial VOC/oil liquid mixture concentrations in a calcium silicate matrix, under low temperature heating and vacuum boundary conditions that are representative of potentially desirable "in-drum desorption" conditions.
\end{abstract}

The results of these tests indicate that reduced operating pressures have a potential for significantly enhancing the rate of thermal desorption experienced from a liquid organic/oil solidified "sludge" waste. Furthermore, the results indicate that in-drum thermal desorption can be performed on organic sludge wastes, at reduced pressures, while maintaining an operating temperature sufficiently low to prevent destruction of the waste drum packaging materials (confinement) surrounding the waste. The results also indicate that VOC release behavior/rates in the vacuum thermal desorption process cannot be represented by a simple liquid-liquid mass-diffusion model, since overall mass release rates observed are generally two orders of magnitude greater than predicted by simple liquid-liquid mass diffusion. This is partially attributed to the effects of the transient temperature profiles within the sludge during heat up; however, the primary cause is thought to be micro boiling of the volatile organics within the simulated sludge. Micro boiling of VOC's would be expected to occur in localized volumes within the organic sludge where temperatures exceed the volatile organic saturation temperature sufficiently to form vapor bubbles. Further model based evaluations reflecting the transient temperatures, local boiling, and subsequent vapor in liquid/sludge transport conditions are needed, with supporting controlled testing of the vacuum-aided thermal desorption process at small and full-scale conditions in order to fully develop this process. 


\section{CONTENTS}

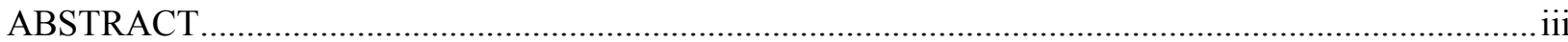

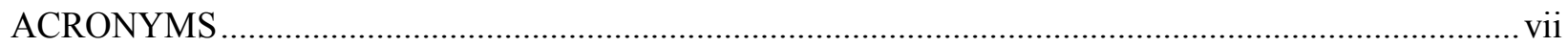

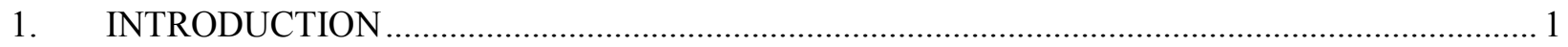

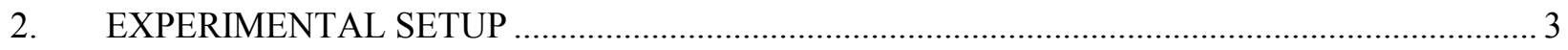

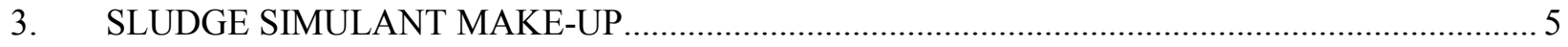

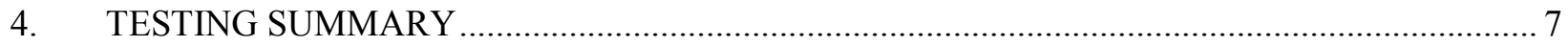

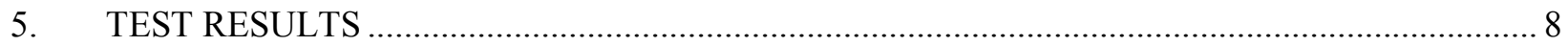

5.1 Pressure and Temperature Effects on Thermal Desorption Rates....................................... 8

5.2 Desorption Rate Evaluation at Various Initial VOC Concentrations, Sludge Volumes, and

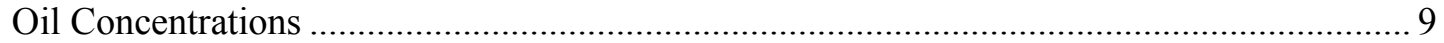

5.3 Observed Temperature Gradients Within Simulated Sludge Samples at Various Test Conditions

5.4 Effective Mass Diffusion Coefficients for Thermally Desorbing VOCs, at Various Test Conditions

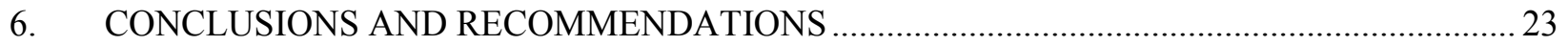

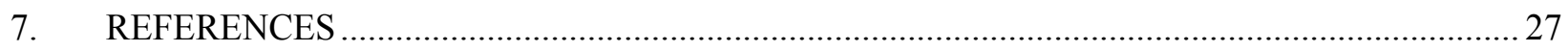

Appendix A —Sludge Project Run Information ............................................................................. A-1

FIGURES

1. Schematic diagram of experimental apparatus for thermal desorption testing of simulated sludges. [Legend: $\mathrm{MFC}=$ mass flow controller, $\mathrm{PCV}=$ pressure control valve] ...................................... 3

2. Photograph of experimental set-up showing the gas chromatograph and vacuum oven.................. 4

3. Typical chromatogram generated using the GC-MS system. [Peak 1 - Methanol; Peak 2 1,1,1-Trichloroethane; Peak 3 - Carbon tetrachloride; Peak 4 - Trichloroethylene; Peak 5 -

Tetrachloroethylene.]

4. Photograph of a typical sludge container (1-quart nominal size) and the temperature probes utilized during vacuum-aided thermal desorption testing. 5

5. Typical $\mathrm{CCl}_{4}$ versus time evolution curve for thermal desorption treatment of a simulated sludge. 
6. Typical TCA, TCE, and PCE versus time evolution curves for thermal desorption treatment of a simulated sludge.

7. Comparison of thermal desorption test conducted at a nominal 1-quart size utilizing sludge simulants containing all the VOCs (VOCs) vs. only carbon tetrachloride $\left(\mathrm{CCl}_{4}\right) \ldots \ldots \ldots \ldots . . . . .12$

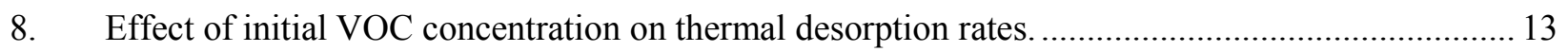

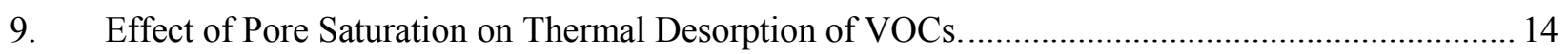

10. VOC Thermal Desorption Profile, As a Function of Sludge Volume............................................ 14

11. Centerline Temperature Profiles for a 1-qt Thermal Desorption Test $\left(80^{\circ} \mathrm{C}, 200\right.$ Torr $) \ldots \ldots \ldots \ldots \ldots \ldots . . . . .16$

12. Radial Temperature Profiles for a 1-qt Thermal Desorption Test $\left(80^{\circ} \mathrm{C}, 200\right.$ Torr $) \ldots \ldots \ldots \ldots \ldots \ldots \ldots . . . . . . . .16$

13. Oven Temperature Profiles for a 1-qt Thermal Desorption Test $\left(80^{\circ} \mathrm{C}, 200\right.$ Torr $) \ldots \ldots \ldots \ldots . . . .17$

14. Comparison of center-point temperature profiles for 1-quart test volumes with low (6-7 $\mathrm{wt} \%)$, medium (23-26 wt\%) and high (45-50 wt\%) VOC concentrations. Testing conditions: $80^{\circ} \mathrm{C}, 200$ Torr.

15. Comparison of centerline temperature profiles for 1-quart, 2-quart, and 4-quart nominal testing volumes containing approximately $10 \mathrm{wt} \%$ added VOC's. Testing conditions: 80 ${ }^{\circ} \mathrm{C}, 200$ Torr.

16. Measured vs. Modeled VOC Desorption Profile for a 4-quart, Unsaturated Sludge, Containing 7-8 wt \% VOCs.

17. Comparison of Measured Mass Desorption Profile with Modeled Mass Desorption Profiles, Using Constant and Varying Effective Mass Diffusivities (1-quart, Oil-Saturated Sludge, $21 \mathrm{wt} \%$ VOCs)

\section{TABLES}

1. Physical properties of selected VOCs used in vacuum-aided thermal desorption testing 7

2. Summary of Lab-Scale Thermal Desorption Tests Performed at Various Testing Conditions.

3. Position of temperature probes within simulated sludge container for the various testing volume investigated. ${ }^{\mathrm{a}, \mathrm{b}}$......

4. Comparison of Thermal Desorption Rates at Various Desorption Pressures and Temperatures.

5. Calculated Average Mass Diffusion Coefficients for Each Lab-Scale Test Condition $\left(80^{\circ} \mathrm{C}, 26-30 \mathrm{kPa}\right)$. 


\section{ACRONYMS}

\begin{tabular}{ll}
$\mathrm{CCl}_{4}$ & carbon tetrachloride \\
DOE & Department of Energy \\
GC & gas chromatograph \\
GGT & gas generation testing \\
INEEL & Idaho National Engineering and Environmental Laboratory \\
MFC & mass flow controller \\
PCB & polychlorinated bi-phenyl \\
PCE & tetrachloroethylene \\
PCV & pressure control valve \\
TCA & 1,1,1-trichloroethane \\
TCE & trichloroethylene \\
TMFA & Transuranic and Mixed Waste Focus Area \\
TRU & transuranic \\
TRUPACT-II & transuranic package transporter \\
VOC & volatile organic compounds \\
WAC & waste acceptance criteria \\
WIPP & Waste Isolation Pilot Plant \\
\hline
\end{tabular}




\section{Low-Temperature, Vacuum-Aided Thermal Desorption Studies on a Simulated Organic Sludge Waste}

\section{INTRODUCTION}

In response to public comments associated with the potential use of incineration by the Idaho National Engineering and Environmental Laboratory's (INEEL's) Advanced Mixed Waste Treatment Facility, the U.S. Department of Energy (DOE) conducted an independent blue-ribbon panel review of emerging processing technology alternatives to incineration for the potential treatment of transuranic (TRU) and alpha contaminated mixed wastes within the DOE complex. ${ }^{1}$ Several preferred alternative technologies, including thermal desorption, were identified and recommended for further evaluation and potential developmental support for DOE applications. As a result the DOE EM Office of Science and Technology began further limited evaluations and development support for selected alternatives through its Transuranic and Mixed Waste Focus Area (TMFA) program.

A potential primary waste application of concern involves the large number of TRU-contaminated organic sludge drums at the INEEL and Rocky Flats. Many of these drums are expected to exhibit high flammable gas (hydrogen) concentrations and/or total gas/vapor pressures under waste certification test conditions currently required for transport to an off-site repository (such as the Waste Isolation Pilot Plant [WIPP]). Based upon current gas generation testing (GGT) experience at the INEEL over half of the organic sludge wastes would be expected to exceed current requirements for maximum allowable gas generation rates. The use of an alternative treatment equivalent to incineration would eliminate the organic materials in the waste that are expected to be the prime cause for failing the total gas pressure and/or flammable gas concentration tests associated with transportation certification. Improved understanding of this process may also allow for simple analytical (predictive model) based certification of the treated waste residuals, for transportation to WIPP.

Various alternative high temperature destructive and thermal desorption technologies exist that might be utilized for this purpose in ex-situ (out of drum) waste processing. Nevertheless, the TMFA has recognized the potential for significantly reduced processing risks (both actual and perceived) and reduced processing/facility complexity that might be obtained by simply utilizing a lower temperature/energy and minimally intrusive (in-drum) waste processing approach, such as in-drum vacuum assisted low temperature thermal desorption. As a result the current exploratory test studies reported here-in were undertaken as an initial step in the evaluation and potential further applications development of an in-drum vacuum thermal desorption approach for eliminating gas generation limitations in transuranic organic sludge wastes.

The GGT currently required for off-site transport of the TRU-contaminated organic sludge drums to WIPP involves placing the drums in a sealed container, heating the drums to $57^{\circ} \mathrm{C}$, and determining the increased total gas pressure and flammable gas concentration experienced by the drum, over a 24-hr period. The determined rates of gas pressure/flammable gas concentration build-up are then conservatively assumed to represent potential long-term steady gas generation and pressure buildup rates for the drums, for comparison to allowable limits for transport in the TRU package transporter (TRUPACT-II). Initial GGTs that were performed on 35 drums of IDC-003 waste at the INEEL ${ }^{2}$ found that 19 of the drums failed the transportation waste acceptance criteria (WAC). Fifteen of the drums failed on total gas rate limits, while seven of the 19 drums exhibited unacceptable rates of flammable gas generation (four of the tested drums failed both total gas and hydrogen limits), and one was discontinued (failed) due to excessive pressure with respect to test system/procedure limits. 
The primary reason for such high GGT failure rates by the IDC-003 waste drums is thought to be the large volume of volatile organic contaminants (VOCs) that are typically present in these organic sludge wastes. These VOCs are expected to volatilize from the organic sludge wastes at the elevated temperature $\left(57^{\circ} \mathrm{C}\right)$ required for GGT. ${ }^{3}$ The resulting volatilization causes a significant increase in the total gas pressure within the sealed testing container, over time. Applying thermal desorption to the sludge in advance of the total gas pressure tests, however, would eliminate the volatile organic materials from the sludge as a contributor to total gas pressure.

The high hydrogen generation rates, determined via current waste certification gas generation testing of organic sludges, are inconsistent with expected typical radiolytic hydrogen generation rates of the primary individual organic materials present (VOC/oil mixture). It has been hypothesized that the unexpected high flammable gas (hydrogen) generation rates in the GGTs could include contributions from previously generated and stored/captured radiolytic hydrogen dissolved in the VOC/oil mixture over time. ${ }^{4}$ Hydrogen release may also be caused by some other low temperature activated release mechanism or reaction activated by the elevated temperature in the gas generation test (e.g. temperature activated radio-catalyzed release of hydrogen from the radiation damaged oil/voc mixture or enhanced chemical reactions with air/oxygen). In any case, thermal desorption processing at temperatures exceeding the certification gas generation temperature would be expected to activate the mechanisms and release the excess "stored and/or incipient generated" hydrogen from the sludge along with the VOC vapor release. Subsequent certification testing for flammable gas generation would then be expected to show minimal and predictable gas generation rates.

A primary reason for evaluating vacuum-assisted low-temperature thermal desorption processing (indrum) as a potential treatment for eliminating gas generation rate limitations on these wastes, is to simplify transuranic contamination control and waste handling issues during processing by maintaining the integrity of the drum as a filtered confinement. Therefore, a fundamental objective of these initial tests was to provide exploratory data on VOC thermal desorption behavior and rates from surrogate sludge material, while operating at temperatures sufficiently low to preclude degradation of the actual waste packaging in the organic sludge waste drums. Testing was therefore concentrated on desorption temperatures below $85^{\circ} \mathrm{C}$, the maximum recommended service temperature and heat-distortion temperature for the polyethylene liner, and the maximum recommended continuous-use temperature for the neoprene gasket seal. ${ }^{5}$

The focus of these initial lab-scale vacuum-aided desorption tests was to provide exploratory data on temperature profiles and rates of VOC desorption expected from known small volumes of surrogate organic sludge, at several representative applied temperatures, reduced pressures, and initial VOC/oil mixture concentrations. Data/results from these initial tests were expected to lead to further controlled lab-scale tests and data to be used in establishing controlling parameters and developing future computational models for use in designing a potential full-drum scale vacuum thermal desorption test bed system.

The desorption testing reported here-in was performed utilizing small open top containers of simulated organic sludge at nominal volumes of 1-, 2-, and 4-quarts. Each container was heated in a convective vacuum oven at controlled temperatures of $80^{\circ} \mathrm{C}$ or $60^{\circ} \mathrm{C}$, reduced pressures of 200 or 500 torr and high, medium, or low VOC concentrations (approximately 40, 20, and $7 \mathrm{wt} \%$, respectively). Temperatures were measured at various locations in the sludge and oven and desorbed VOC's were measured with a gas chromatograph and mass selective detector. End state weight loss measurements were also taken. The experimental apparatus, sludge simulant makeup, and conditions tested are described in the following report sections 2, 3, and 4 respectively. Primary test results and evaluations are described in Section 5 and conclusions and recommendations are provided in Section 6. 
The exploratory scope of these initial laboratory-scale thermal desorption studies did not include any direct test evaluation of hydrogen release/transport from a surrogate organic sludge, during thermal desorption. Considering available information on potential solubility of hydrogen in an oil/VOC mixture it is expected that the hydrogen dissolves in the VOC portion of the organic liquid, rather than the oil itself, justifying an assumption that stored hydrogen releases with volatilizing VOCs. ${ }^{6}$ Furthermore, achieving incorporation of any significant quantity of dissolved hydrogen into the simulated organic sludge would have required using elevated pressures and specialized equipment that was not available for this study. The issue of hydrogen release, during thermal desorption will need to be explored more explicitly in future thermal desorption studies.

\section{EXPERIMENTAL SETUP}

A simple schematic diagram of the experimental apparatus used in the laboratory-scale thermal desorption tests is presented in Figure 1. A photograph of the experimental set-up is shown in Figure 2. The experimental setup was centered around a 42.5-1 vacuum oven (Isotemp Model 282A, Fisher Scientific). The oven was used to convectively heat the sludge container while operating at a fixed temperature and an operating pressure significantly below atmospheric pressure. Vapors generated from simulated sludge in the vacuum oven, during thermal desorption testing, were diluted with a constant flow of nitrogen gas (5.0 standard $\mathrm{L} / \mathrm{min}$ ). The flow of nitrogen gas was regulated to the oven via a mass flow controller (MFC), (MKS, Model 1159B). To maintain the vacuum oven at a desired vacuum level, a pressure control valve (PCV) (MKS Model 640A) was installed on the outlet of the oven. The control valve was operated by a multi-channel readout (MKS, Model 247C) while the pressure in the vacuum oven was monitored via a capacitance manometer (MKS, Model 122A) and readout (MKS, Model PDR$\mathrm{C}-2 \mathrm{C}$ ). Flow for the entire off-gas vacuum was provided by a rotary vacuum pump (Fisher, Maxima, Model M8CG).

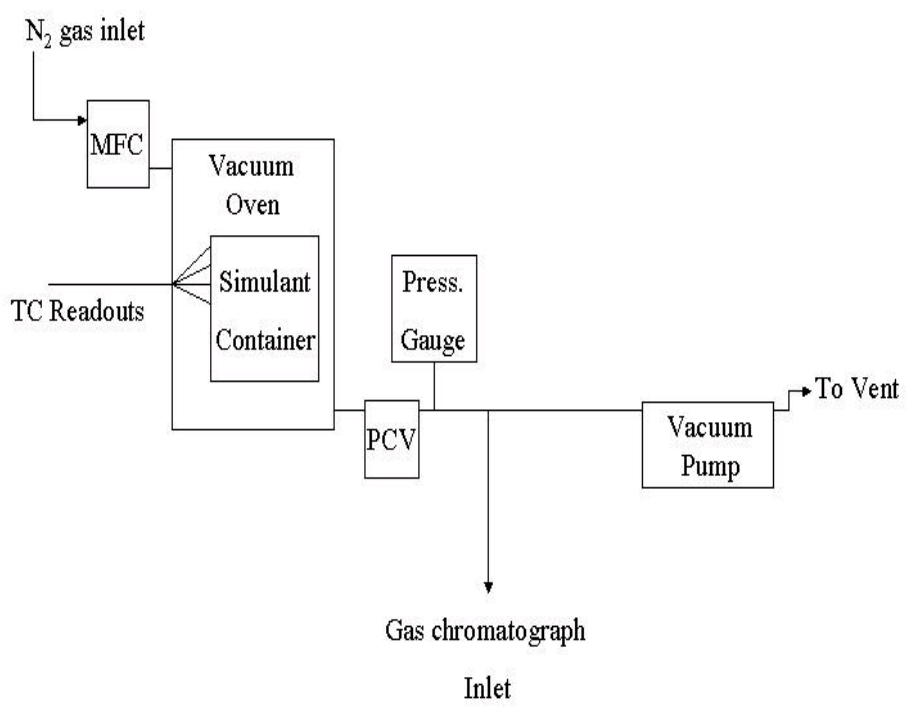

Figure 1. Schematic diagram of experimental apparatus for thermal desorption testing of simulated sludges. [Legend: $\mathrm{MFC}=$ mass flow controller, $\mathrm{PCV}=$ pressure control valve] 


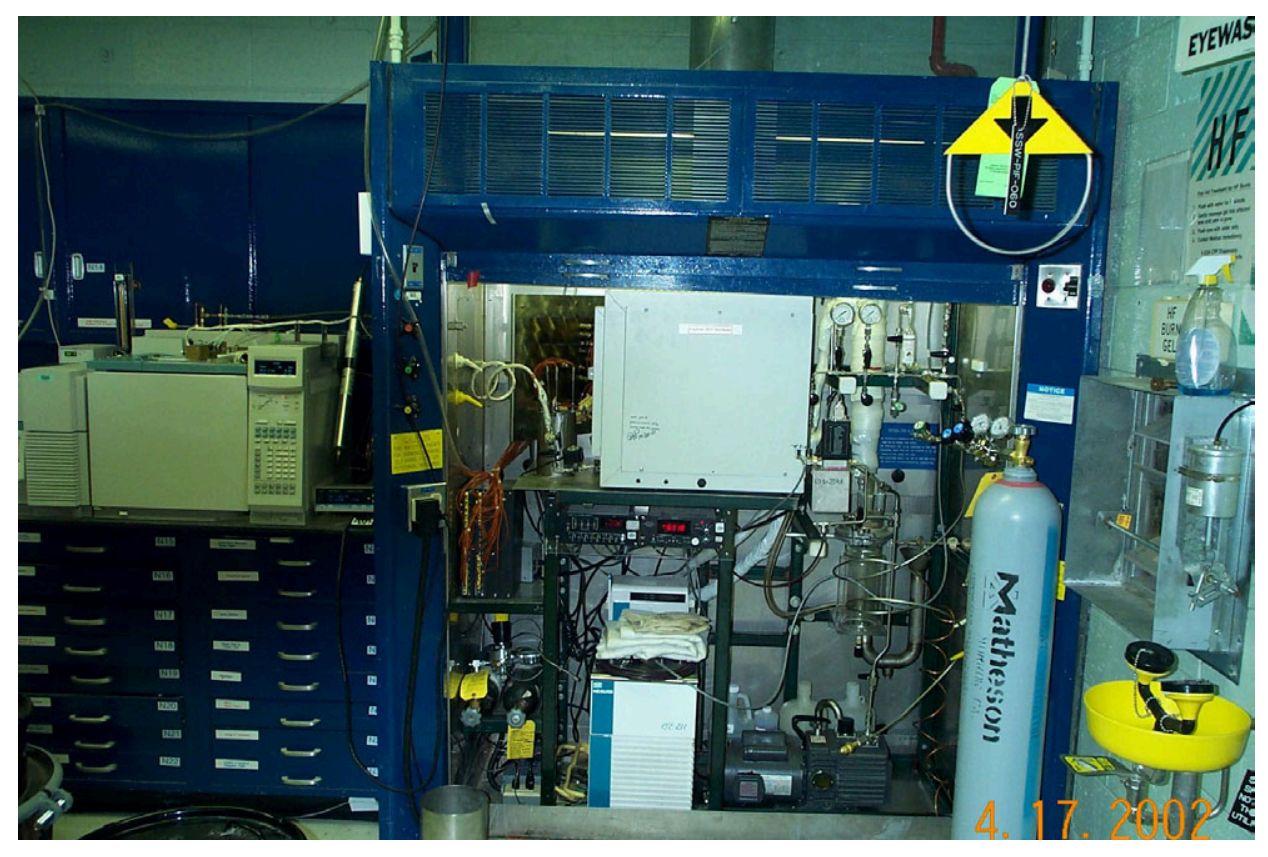

Figure 2. Photograph of experimental set-up showing the gas chromatograph and vacuum oven.

Gases from the vacuum-oven were sent to the building off-gas system. A representative portion $(10-30 \mathrm{ml} / \mathrm{min})$ of the off-gas stream was analyzed via a gas chromatograph (GC, Agilent, Model $6890 \mathrm{~N}$ ), equipped with a mass selective detector (Agilent, Model 5973). The GC system was equipped with a cryogenic valve that allows operation of the GC oven at sub-ambient temperatures, to provide improved separation of the halogenated hydrocarbons.

The purpose of the nitrogen gas addition to the vacuum oven was to minimize the residence time of vapors within the oven (thereby providing a more rapid time response to the GC), while minimizing oxidation of the VOC vapors produced during thermal desorption testing. A gas mixture (Matheson Tri-Gas) containing known concentrations of the targeted VOCs (1,1,1-trichloroethane [TCA], carbon tetrachloride $\left[\mathrm{CCl}_{4}\right]$, trichloroethylene [TCE], and tetrachloroethylene [PCE]) was used to calibrate the response of the mass-selective detector. A typical chromatogram generated using the GC is shown in Figure 3.

The temperatures experienced by the simulated sludge during thermal desorption testing were monitored by several thermocouple probes, each of which contained five Type K thermocouples (Omega Engineering), spaced axially within the probe sheath at 2-in. intervals from the tip. The probes were placed at known axial and radial locations within the sludge simulant (see table 3). A photograph of a typical sludge container and temperature probes is shown in Figure 4. The standard error associated with the Type $\mathrm{K}$ thermocouples was $\pm 0.3^{\circ} \mathrm{C}$, at temperatures of $80^{\circ} \mathrm{C}$. The temperature profiles from these thermocouples were measured by recording the output of the thermocouples with a data logger (IOTech, Chartscan Model 1400) equipped with thermocouple monitoring modules (IOTech, Model CSN14/TC/P). The data logger was interfaced to a computer that was used for data storage and manipulation. 


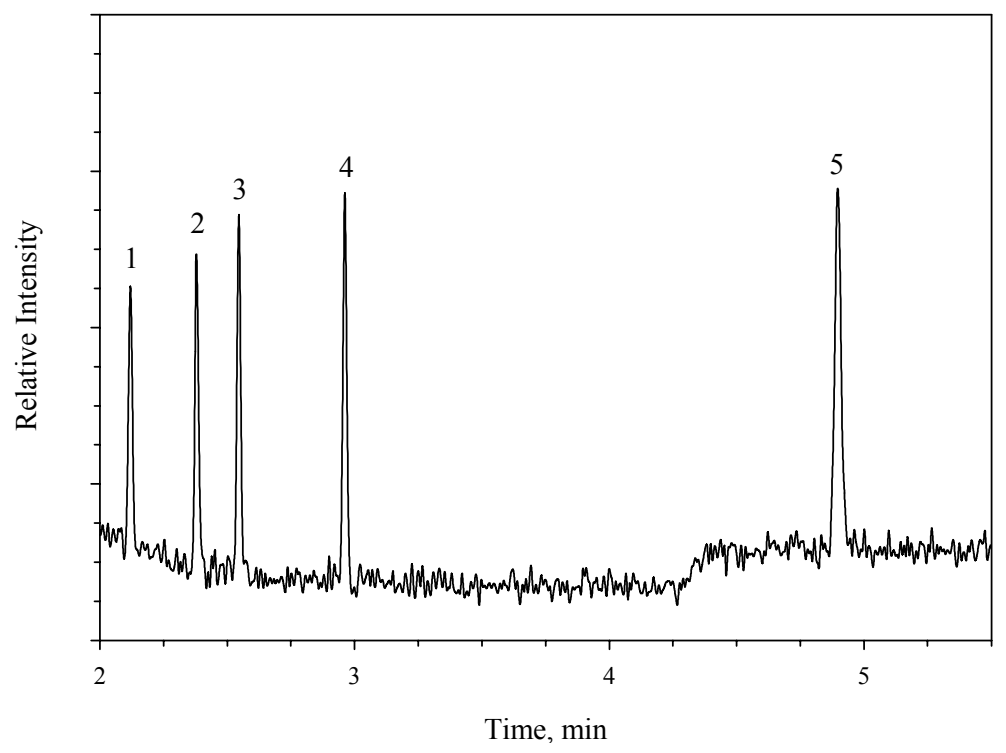

Figure 3. Typical chromatogram generated using the GC-MS system. [Peak 1 - Methanol; Peak 2 1,1,1-Trichloroethane; Peak 3 - Carbon tetrachloride; Peak 4 - Trichloroethylene; Peak 5 - Tetrachloroethylene.]

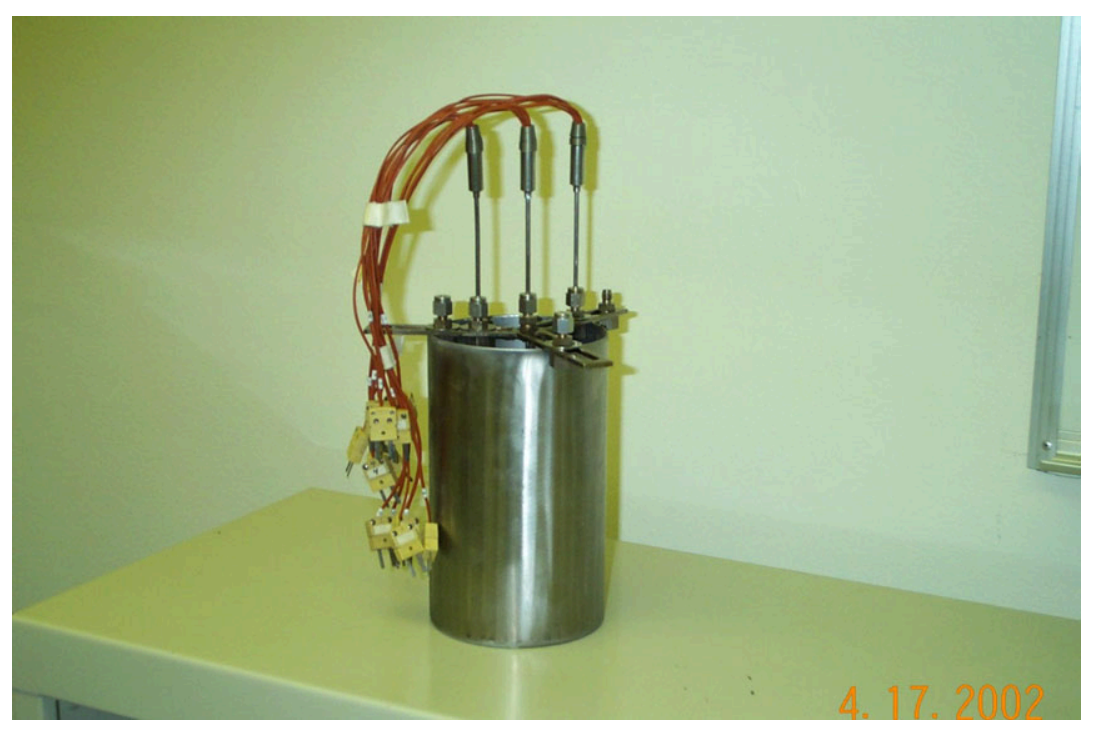

Figure 4. Photograph of a typical sludge container (1-quart nominal size) and the temperature probes utilized during vacuum-aided thermal desorption testing.

\section{SLUDGE SIMULANT MAKE-UP}

The composition of surrogate organic sludge used in the lab-scale thermal desorption tests was based on projected compositions of the IDC-003 sludge that was originally prepared at the Rocky Flats Plant, prior to its disposal at the INEEL (the sludge is also referred to as RFP Series 743 organic sludge). The IDC-003 sludge composition was selected because of its larger total volume and better known compositional information than the other organic sludge wastes suitable for potential thermal desorption 
activities. In addition, a test bases assumption was that the rate of VOC desorption from the sludge would be controlled by the VOC's mass diffusivity in Texaco Regal Oil, not the effect of absorbents. As a result, the tests using silicate sorbent were expected to be representative of other organic sludge wastes currently in storage at the INEEL, such as the Series 801 Oasis sludge (which are solidified in gypsum cement), and the RFP Series 744 sludge (which are solidified in a mixture of Portland and magnesia cement). ${ }^{7}$

The bulk materials present in IDC-003 sludge generally consist of various VOCs, oils, calcium silicate, and diatomaceous earth. For test simplification purposes, it was decided to use Regal Oil R\&O 32 (Texaco) to represent all of the oils in the IDC-003 sludge simulations. In addition, the bulk of the chlorinated hydrocarbons present in the organic sludge wastes can be represented by a mixture of only four VOCs--1,1,1-trichloroethane [TCA]; carbon tetrachloride $\left[\mathrm{CCl}_{4}\right]$; trichloroethylene [TCE]; and tetrachloroethylene [PCE]). This representation is primarily based on data from Clements (1982), which identified these four VOCs as the primary VOCs in buried IDC-003 organic sludge drums. In addition, data from Barber, Carney and Demirgian ${ }^{8}$ indicate that these are the only VOCs found to be present at substantial concentrations in IDC-003 wastes, that do not have boiling points below $50^{\circ} \mathrm{C}$. The TCA, $\mathrm{CCl}_{4}$, TCE, and PCE were obtained from Aldrich and used as received. General physical properties of the VOCs used in this work are presented in Table 1.

Each sludge simulant was prepared on a test-by-test basis, with the resultant sludge generally refrigerated following its make-up. The VOCs that were used in each sludge simulation were also pre-refrigerated prior to being added to the sludge. Refrigeration was used to minimize the amount of VOCs that would volatilize away from the sludge simulant during and after mixing. Even with the use of pre-refrigeration, volatilization of 25-33 wt \% of the added VOCs was typically experienced during the sludge make-up phase.

The initial step in the sludge simulant preparation involved mixing the Regal Oil with calcium silicate and diatomaceous earth. In general, care was taken to keep the concentrations of Regal Oil, calcium silicate, and diatomaceous earth relatively constant for each sludge make-up. Thus, variations in oil/absorbent volumes should not significantly bias the observed thermal desorption rates from each test. The relative component ratios targeted for each lab-scale test were $66.3-w t \%$ oil, 26.7 -wt $\%$ calcium silicate, and 7.0 -wt \% diatomaceous earth, respectively.

In contrast, the VOC concentration in each sludge simulant varied from relatively dilute levels (approx. $6 \mathrm{wt} \%$, after mixing) to relatively concentrated levels (approx. $50 \mathrm{wt} \%$, after mixing). The purpose of varying the VOC concentration was to evaluate thermal desorption rates as a function of initial VOC concentrations. The high VOC concentration tests were based on recent historical evidence postulating the possibility of larger VOC concentrations in IDC-003 sludge than originally estimated. ${ }^{9}$ However, the lower VOC concentration tests were evaluated due to recent sampling evidence indicating that the expected concentrations of VOCs still present in the IDC-003 sludges may be substantially less than what was originally placed in the sludge. ${ }^{8}$

In addition, some lab-scale tests were performed with a mixture of the four VOCs, while a larger portion of the tests was performed with $\mathrm{CCl}_{4}$ as the only VOC present in the sludge (used to represent all of the VOCs). This provided data to evaluate the similarity of total VOC thermal desorption rates determined with a mixture of VOCs vs. $\mathrm{CCl}_{4}$ alone, to determine if a binary liquid mixture $\mathrm{CCl}_{4}$ and Regal Oil sludge would be reasonably representative of a sludge containing multiple VOCs in oil. Use of a binary liquid model, evaluating the diffusion of $\mathrm{CCl}_{4}$ out of Regal Oil, would greatly simplify future testing and computational modeling-based analysis of the thermal desorption process, provided such a mixture model could reasonably represent the actual behavior for IDC-003 organic sludge wastes containing multiple VOCs. 
Table 1. Physical properties of selected VOCs used in vacuum-aided thermal desorption testing.

\begin{tabular}{cccccc}
\hline Compound & $\begin{array}{c}\text { Molecular Weight } \\
\text { g/mol }\end{array}$ & $\begin{array}{c}\text { Melting Point } \\
{ }^{\circ} \mathrm{C}\end{array}$ & $\begin{array}{c}\text { Boiling Point } \\
{ }^{\circ} \mathrm{C} @ \text { @ 760 Torr }\end{array}$ & $\begin{array}{c}\text { Boiling Point } \\
{ }^{\circ} \mathrm{C} @ \text { 200 Torr }\end{array}$ & $\begin{array}{c}\text { Density } \\
\mathrm{g} / \mathrm{mL} 25^{\circ} \mathrm{C}\end{array}$ \\
\hline $\mathrm{TCA}$ & 133.41 & -30.4 & 74.1 & 36.2 & 1.339 \\
$\mathrm{CCl}_{4}$ & 153.82 & -23.0 & 76.5 & 38.3 & 1.594 \\
$\mathrm{TCE}$ & 131.29 & -73.0 & 87.0 & 48.0 & 1.464 \\
$\mathrm{PCE}$ & 165.83 & -19.0 & 121.1 & 79.8 & 1.623 \\
\hline
\end{tabular}

Lab-scale testing was performed at three different surrogate sludge volumes. The volumes used were approximately $830 \mathrm{~mL}, 1700 \mathrm{~mL}$, and $3100 \mathrm{~mL}$, which correspond (nominally) to 1-quart, 2-quart, and 4-quart volumes, respectively. The different sludge volumes were intended to provide data that would be used to evaluate how VOC thermal desorption behavior/rates might be affected by scale. In general all of the sludge volumes had an aspect ratio (height to diameter) of 3:2, similar to the aspect ratio for actual 55gallon $(208 \mathrm{~L})$ waste drums. The only exception was the larger-scale (nominal 4-quart) sludge volume, which had a reduced aspect ratio of 5:4 due to lab-scale equipment limitations (i.e., oven height).

\section{TESTING SUMMARY}

A total of 17 successful lab-scale thermal desorption tests were performed on surrogate material simulations of the IDC-003 organic sludge. The tests were performed at various initial VOC concentrations $(6-50 \mathrm{wt} \%)$ and volumes $(715-3130 \mathrm{ml})$. Fifteen of the tests were performed at an oven temperature of $80 \pm 1{ }^{\circ} \mathrm{C}$ and a pressure of $200 \pm 10$ Torr. The other two tests were conducted at $60 \pm 1{ }^{\circ} \mathrm{C}$, with one of the tests conducted at $200 \pm 10$ Torr and the other conducted at $500 \pm 10$ Torr. Details of the lab-scale test conditions are summarized in Table 2. The table includes information on the number of tests at each condition and the VOC simulation type $\left(\mathrm{CCl}_{4}\right.$ only, vs. all four VOCs).

Temperature data was obtained for all 17 of the tests. However, data on mass desorption rates (as a function of time) was only obtained for the 15 thermal desorption tests that were performed at $80^{\circ} \mathrm{C}$. A non-functioning $\mathrm{GC}$ was the primary reason for no mass desorption rate data being obtained on the two $60^{\circ} \mathrm{C}$ tests. However, data was obtained on the total desorbed weight losses experienced by the $60^{\circ} \mathrm{C}$ tests. This data was then used to compare the average mass desorption rates for the entire testing period with those average rates for the tests that were performed at $80^{\circ} \mathrm{C}$ and 200 Torr.

There were also a number of preliminary tests conducted for test system shakedown. This included heat-up of oil alone and simulated sludges containing only oil and calcium silicate, without any VOCs. Some of these tests involved higher temperatures and reduced vacuum. Data from these preliminary shakedown tests is included as a part of the full test data set provided in Appendix A, for completeness. It is not, however, evaluated further in this report.

The temperature profile data from each of the tests is expected to be potentially useful in anticipated future engineering efforts to develop and verify computational models predicting both transient thermal profile response (within the sludge) and bulk mass release determinations from the thermally desorbed surrogate sludge volumes. Table 3 provides a description of the positions of the thermocouple probes used to monitor the temperature profiles within the simulated sludge samples. 
Table 2. Summary of Lab-Scale Thermal Desorption Tests Performed at Various Testing Conditions.

\begin{tabular}{|c|c|c|c|c|c|}
\hline Temperature & Pressure & $\begin{array}{c}\text { Init. VOC } \\
\text { Concentration } \\
\end{array}$ & $\begin{array}{c}\text { Nominal Sludge } \\
\text { Volume }\end{array}$ & $\begin{array}{c}\text { Oil } \\
\text { Concentration } \\
\end{array}$ & Number of Tests \\
\hline $80^{\circ} \mathrm{C}$ & 208-223 Torr & $45-50$ wt $\%$ & 1-quart & $419 \mathrm{~g} / 1$ & $2\left(1 \mathrm{CCl}_{4}, 1 \mathrm{VOCs}\right)$ \\
\hline $80^{\circ} \mathrm{C}$ & 198-203 Torr & $6-7$ wt $\%$ & 1-quart & $370-380 \mathrm{~g} / 1$ & $3\left(2 \mathrm{CCl}_{4}, 1 \mathrm{VOCs}\right)$ \\
\hline $80^{\circ} \mathrm{C}$ & 200-204 Torr & $7-8$ wt $\%$ & 4-quart & $395-405 \mathrm{~g} / 1$ & $3\left(2 \mathrm{CCl}_{4}, 1 \mathrm{VOCs}\right)$ \\
\hline $80^{\circ} \mathrm{C}$ & 199-203 Torr & $7-8$ wt $\%$ & 2-quart & $398-409 \mathrm{~g} / 1$ & $3\left(2 \mathrm{CCl}_{4}, 1 \mathrm{VOCs}\right)$ \\
\hline $80^{\circ} \mathrm{C}$ & 200-203 Torr & $23-26$ wt $\%$ & 1-quart & $350-410 \mathrm{~g} / 1$ & $3\left(2 \mathrm{CCl}_{4}, 1 \mathrm{VOCs}\right)$ \\
\hline $80^{\circ} \mathrm{C}$ & 200-203 Torr & $21 \mathrm{wt} \%$ & 1-quart & $550 \mathrm{~g} / 1$ & 1 (VOCs) \\
\hline $60^{\circ} \mathrm{C}$ & $\sim 200$ Torr & $40 \mathrm{wt} \%$ & 1-quart & $419 \mathrm{~g} / 1$ & 1 (VOCs) \\
\hline $60^{\circ} \mathrm{C}$ & $\sim 500$ Torr & $41 \mathrm{wt} \%$ & 1-quart & $419 \mathrm{~g} / 1$ & 1 (VOCs) \\
\hline
\end{tabular}

Table 3. Position of temperature probes within simulated sludge container for the various testing volume investigated. ${ }^{\mathrm{a}, \mathrm{b}}$

\begin{tabular}{cccccc}
$\begin{array}{c}\text { Nominal Test } \\
\text { Volume }\end{array}$ & $\begin{array}{c}\text { Centerline } \\
\text { Probe }\end{array}$ & $\begin{array}{c}\text { Intermediate } \\
\text { Probe }\end{array}$ & $\begin{array}{c}\text { Middle } \\
\text { Probe }\end{array}$ & $\begin{array}{c}\text { Radial } \\
\text { Probe }\end{array}$ & $\begin{array}{c}\text { Oven } \\
\text { Probe }^{\mathrm{c}}\end{array}$ \\
\hline 1-quart & 0.000 & na & na & $1.222 ”$ & $2.032^{\prime}$ \\
2-quart & 0.000 & $1.085 "$ & $1.935 ”$ & $1.959 ”$ & $2.697 ”$ \\
4-quart & 0.000 & $1.217 ”$ & $2.427 ”$ & $2.676 ”$ & $3.450 ”$
\end{tabular}

a. All dimensions are inches \pm 0.063 "

b. All thermocouple probes are inserted to within $0.250 \pm 0.125$ " of the container bottom

c. 0 ven probe is located along the exterior of the sludge container.

At this time, further consideration of the temperature data from these tests is purposely limited in the subsequent results section to simple presentation and brief discussion of a typical set of time dependent temperature profile data and the contrasting affects of initial VOC concentration and sludge test volume on the temperature response.

The bulk of the subsequent test results discussion is focused upon how the rate of VOC thermal desorption from the sludge is influenced by variations in the initial VOC concentration, sludge volume, thermal desorption boundary condition temperature, sludge pore saturation, and level of applied vacuum pressure.

\section{TEST RESULTS}

\subsection{Pressure and Temperature Effects on Thermal Desorption Rates}

As previously described, two of the preliminary thermal desorption tests were performed on 1-quart nominal $(\sim 740 \mathrm{ml})$ simulated sludge volumes at $60^{\circ} \mathrm{C}$ and either 200 Torr or 500 Torr. These tests were performed early, to evaluate whether reduced pressures, at $60^{\circ} \mathrm{C}$, would affect the rate of VOC desorption experienced, over time. Although no continuous time-dependent data on thermal desorption rates was 
obtained by these tests, the average rates of desorption experienced by these tests could be contrasted with average desorption rates experienced by the other 740 -ml sludge tests, performed under $80^{\circ} \mathrm{C}$ and 200 Torr conditions.

A summary of the results of these three testing conditions is shown in Table 4 . The table shows the total weight loss, desorption time, and calculated average desorption rates for four tests on 1-quart nominal volume sludge samples containing similar initial VOC concentrations ( $40-50 \mathrm{wt} \%)$. As shown by the table, the average rate of thermal desorption increases significantly as the temperature is raised, or the applied pressure is decreased. The reason for this significant effect can be traced to the known vapor pressures for the various VOCs at these conditions. The vapor pressures for the four VOCs at $60^{\circ} \mathrm{C}$ range from 96 to 498 Torr (See Table 1). As a result, at an applied desorption pressure of 500 Torr, the VOCs in the liquid portion of the absorbed sludge have not yet begun to boil. When the pressure is dropped to 200 Torr, however, the applied pressure is substantially less than the vapor pressure of all VOCs but PCE. This causes most of the VOCs in the liquid to begin to boil, enhancing the rate of VOC desorption from the sludges. Even larger VOC desorption rates were experienced at $80^{\circ} \mathrm{C}$ and 200 Torr. This is due to the increased vapor pressures (202 to greater than 760 Torr) and higher boiling rates experienced at $80^{\circ} \mathrm{C}$.

In light of this information (obtained early in the lab-scale evaluation), it became apparent that further thermal desorption tests, on the surrogate IDC-003 organic sludges, should be performed at the highest applied temperature and lowest applied pressure possible, while assuring waste drum packaging integrity. Due to polyethylene liners and neoprene gaskets in actual 55-gallon (208-L) waste drums, future thermal desorption tests needed to be maintained at temperatures less than $85^{\circ} \mathrm{C}$ (the maximum recommended service temperature for these materials). Since the measured temperature variation within the vacuum oven was $\pm 5^{\circ} \mathrm{C}$, it was decided to use $80^{\circ} \mathrm{C}$ as the design temperature for all subsequent thermal desorption tests. Further preliminary shakedown testing also showed that the existing lab-scale test equipment could not be satisfactorily operated at applied desorption pressures below 200 Torr. This was due to the size of the vacuum pump, and the desire to maintain a nitrogen gas sweep flow rate of 5.0 standard L/min into the vacuum oven at all times. Consequently, it was decided to conduct the remaining lab-scale tests at an $80^{\circ} \mathrm{C}$ desorption temperature and an applied pressure of approximately 200 Torr. Keeping the desorption temperature and applied pressure at these levels focused the remaining tests towards an evaluation of how thermal desorption rates are affected by initial VOC concentrations, sludge volume, and the degree of pore saturation originally present in the sludge.

Appendix A contains two tables that describe all the testing performed during this investigation. By consulting the Appendix, the interested reader can locate information, such as notebook citations or detailed parameter listings for the various experiments conducted.

Table 4. Comparison of Thermal Desorption Rates at Various Desorption Pressures and Temperatures.

\begin{tabular}{cccc}
\hline Conditions & Weight Loss & Desorption Time & $\begin{array}{c}\text { Average } \\
\text { Desorption Rate }\end{array}$ \\
\hline $60^{\circ} \mathrm{C}, 500$ Torr & $19.2 \mathrm{~g}$ & $390 \mathrm{~min}$. & $3.0 \mathrm{~g} / \mathrm{hr}$ \\
$60^{\circ} \mathrm{C}, 200$ Torr & $237.3 \mathrm{~g}$ & $1375 \mathrm{~min}$. & $10.4 \mathrm{~g} / \mathrm{hr}$ \\
$80^{\circ} \mathrm{C}, 200$ Torr & $370.3 \mathrm{~g}$ & $1393 \mathrm{~min}$. & $15.9 \mathrm{~g} / \mathrm{hr}$ \\
$80^{\circ}, 200$ Torr & $455.4 \mathrm{~g}$ & $1342 \mathrm{~min}$. & $20.3 \mathrm{~g} / \mathrm{hr}$ \\
\hline
\end{tabular}




\subsection{Desorption Rate Evaluation at Various Initial VOC Concentrations, Sludge Volumes, and Oil Concentrations}

This section summarizes the results of the time-dependent, thermal desorption rates, as a function of initial VOC concentration (6-50 wt \%), and pore saturation. The purpose of this evaluation was to determine if the observed VOC desorption rates were affected by conditions that are not typically ascribed to liquid-liquid mass diffusion theory. In addition the section will evaluate the effect of different sludge volumes on the observed rates of thermal desorption.

The time-dependent thermal desorption rates were determined by initially evaluating (via GC) the measured intensities of each VOC, within the exiting off-gas, as a function of time. If plotted as a function of time, these intensity curves generally rise to a peak intensity within the first $25 \%$ of each testing period, with more concentrated VOC sludge tests exhibiting their peaks within the first $10 \%$ of each test period. The peak intensities are then followed by a decrease in measured intensity, through the remainder of the test. Typical evolution versus time curves for $\mathrm{CCl}_{4}$ and the remaining VOCs are shown in Figures 5 and 6, respectively. To better evaluate thermal desorption profiles, the peak off-gas intensity curves from each test were integrated and added together, to produce total mass fraction release curves for each test, as a function of time (referred to throughout the remainder of this report as a "desorption profile"). These cumulative curves were then used to evaluate thermal desorption behavior, as a function of initial VOC concentration, pore saturation, and test sludge volume.

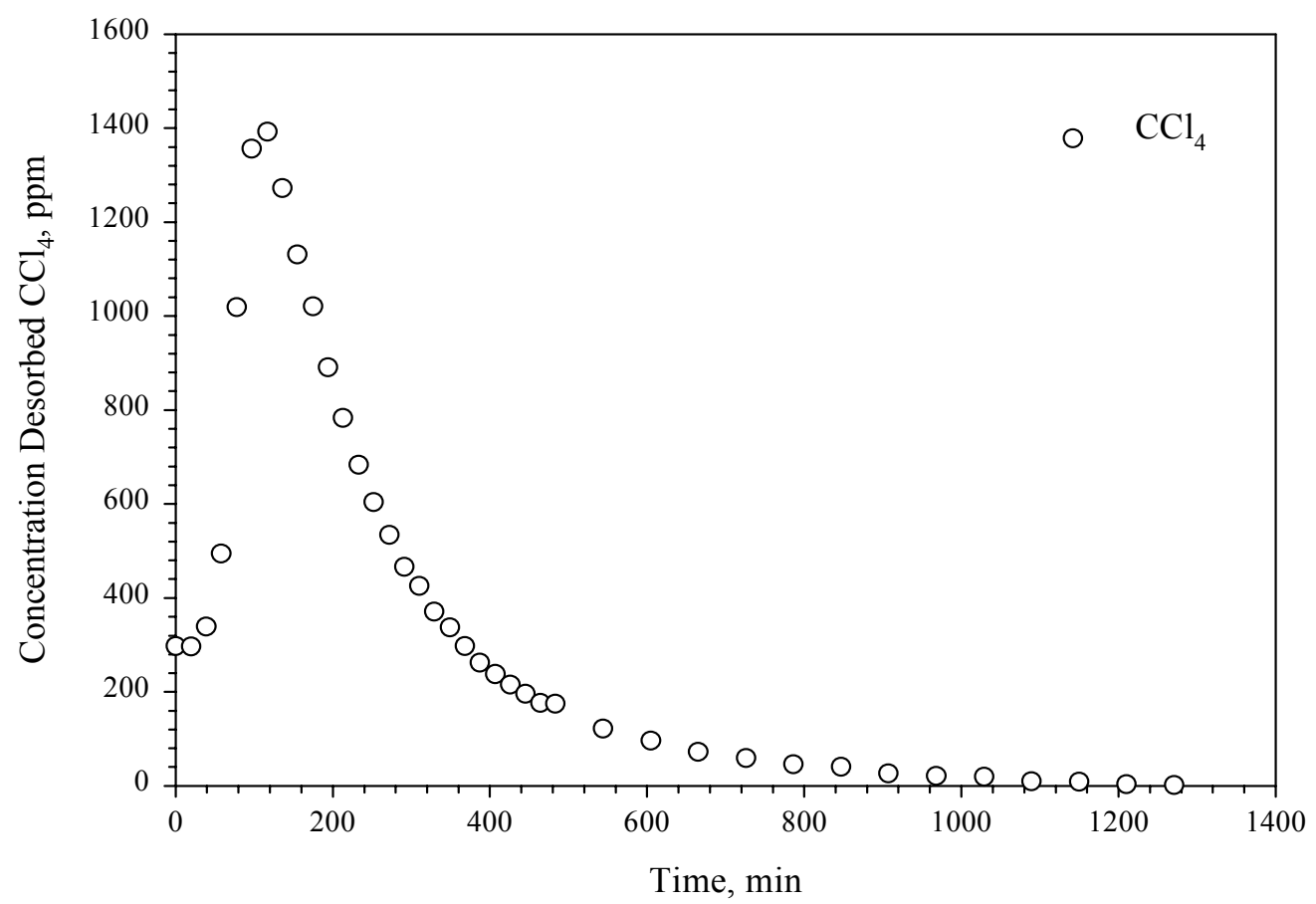

Figure 5. Typical $\mathrm{CCl}_{4}$ versus time evolution curve for thermal desorption treatment of a simulated sludge. 


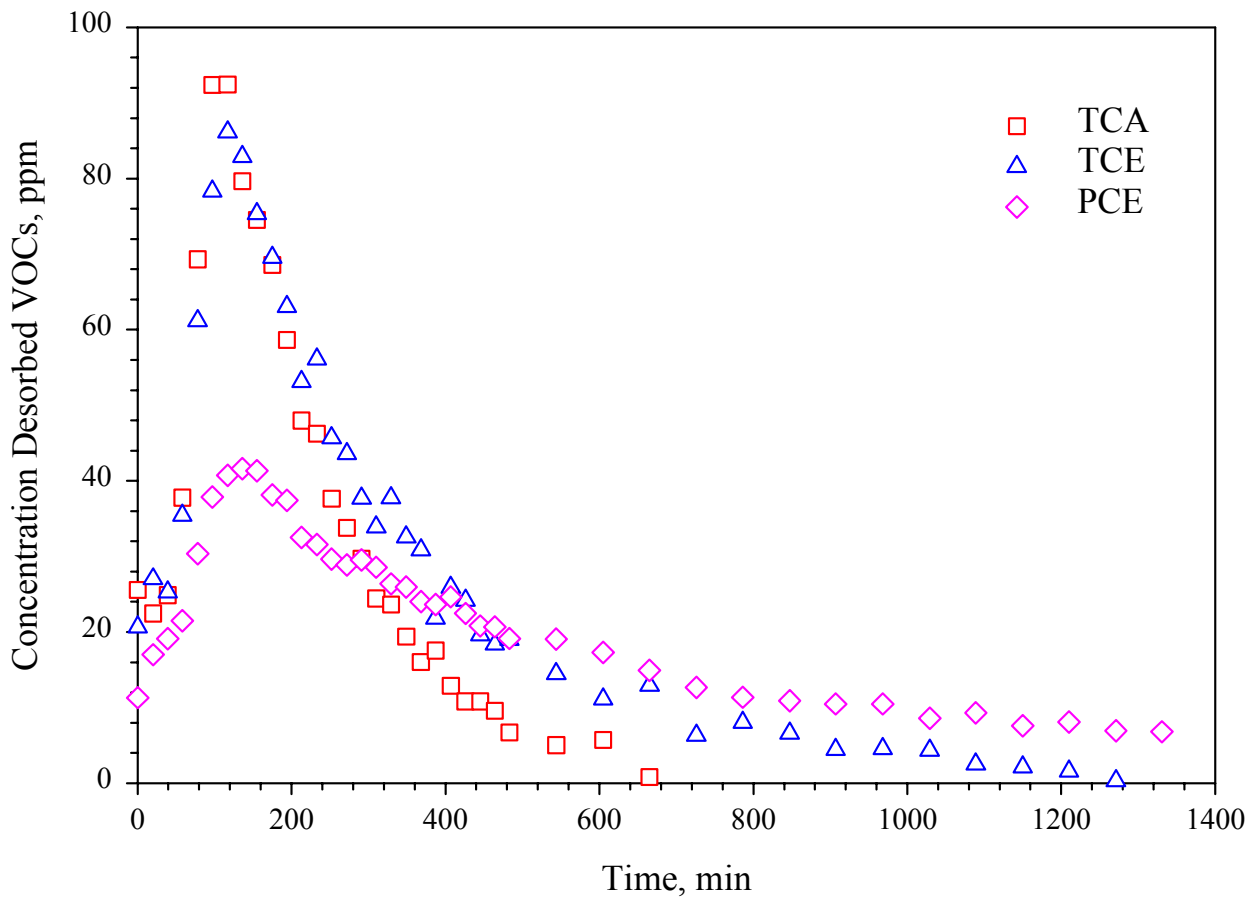

Figure 6. Typical TCA, TCE, and PCE versus time evolution curves for thermal desorption treatment of a simulated sludge.

The first thermal desorption evaluation focused on whether or not desorption data for sludges containing a representative mixture of the four target VOCs $\left(\mathrm{CCl}_{4}, \mathrm{TCA}, \mathrm{TCE}\right.$, and PCE) reasonably matched desorption data for sludges with $\mathrm{CCl}_{4}$ as the lone representative of the four VOCs. As stated, such a match would simplify further test evaluations and future computational modeling of the thermal desorption process, allowing a simple binary liquid diffusion mixture/model to be used. In addition, if the thermal desorption profiles for the "VOC" and " $\mathrm{CCl}_{4}$ " tests were found to be reasonably similar for each testing condition, the desorption mass release curves for the "VOC" tests could be combined with those for the " $\mathrm{CCl}_{4}$ " tests. Combining the curves improves the data base for evaluating thermal desorption rates and calculated mass diffusivities, as a function of the various desorption conditions under evaluation.

Comparisons utilizing sludge simulants containing all four VOCs ("VOC" tests) and sludge simulants containing only carbon tetrachloride ("CCl" tests) were performed for each of the five test conditions, identified in Table 2, where multiple tests had been performed. An example of such an evaluation is shown in Figure 7, which shows the time-dependent mass fraction desorbed for each of the $715-815 \mathrm{ml} \mathrm{lab}$-scale tests that contained $23-26 \mathrm{wt} \%$ VOCs in each sludge simulant. The plot in Figure 7 indicates that similar desorption profiles exist for each of the three tests evaluated at this condition, regardless of whether or not they contained all four $\mathrm{VOCs}$ or $\mathrm{CCl}_{4}$ alone. Similar results were also obtained for the 1-quart sludge tests containing 6-7 wt \% VOCs, and the 1-quart sludge tests containing 45-50 wt \% VOCs. Although the difference in thermal desorption profiles were somewhat larger for the 2-quart and 4-quart sludge tests, containing 7-8 wt \% VOCs, the observed differences between the " $\mathrm{CCl}_{4}$ " tests in each of these conditions were much larger than the differences between the "VOC" tests and the " $\mathrm{CCl}_{4}$ " tests. This comparison showed that desorption data for the "VOC" and " $\mathrm{CCl}_{4}$ " tests could be reasonably combined for each of the five testing conditions, thereby providing a stronger data base from 
which to evaluate other variable effects with improved precision. Accordingly, the "VOC" and " $\mathrm{CCl}_{4}$ " thermal desorption profiles data were combined to produce average and standard deviation cumulative mass release curves (desorption profiles) for each of the five test conditions where multiple lab-scale tests were performed (see Table 2). The resulting calculated thermal desorption profiles were subsequently used to evaluate the effects of the other test conditions/variables (initial VOC concentration, pore saturation, test sludge volume) on the rate of thermal desorption that was experienced.

The effect of initial VOC concentration on thermal desorption rates is shown in Figure 8. Figure 8 was prepared by segregating all of the thermal desorption data from the 1-qt test volumes (those thermally desorbed at $80^{\circ} \mathrm{C}$ and 200 Torr, with oil concentrations less than $420 \mathrm{~g} / \mathrm{L}$ ) into three different initial VOC concentration categories. The categories included a relatively dry sludge concentration of $6-7 \mathrm{wt} \%$ VOCs, a relatively saturated sludge concentration of $45-50 \mathrm{wt} \% \mathrm{VOCs}$, and a moderate sludge concentration of 23-26 wt\% VOCs. Average thermal desorption profiles were then determined for each category of initial VOC concentration, with the resulting averages included in Figure 8.

Figure 8 suggests that there are subtle but significant differences in the rates of thermal desorption experienced by the simulated sludge, as a function of initial VOC concentration. These subtle differences were further confirmed after evaluating the standard deviation curves for each test condition. The results indicate that sludges containing high VOC concentrations (45-50 wt \%) thermally desorb at a rate slower than sludges containing only $23-26 \mathrm{wt} \%$ VOCs, but faster than sludges containing $6-7 \mathrm{wt} \% \mathrm{VOCs}$. A possible reason for such behavior is that the "high VOC" sludges appeared to be more saturated (initially) than either of the sludge conditions containing lower initial VOC concentrations. At higher pore saturations, the liquid-filled pores within the sludge may limit the influence of external surface applied vacuum pressure upon local pressures in regions near the bottom of the sludge volume, due to increased pressure drop (pressure head) across the liquid-filled pores. As a result, the applied vacuum pressure may have less of an effect on the desorption rates for saturated sludges, compared to unsaturated sludges.

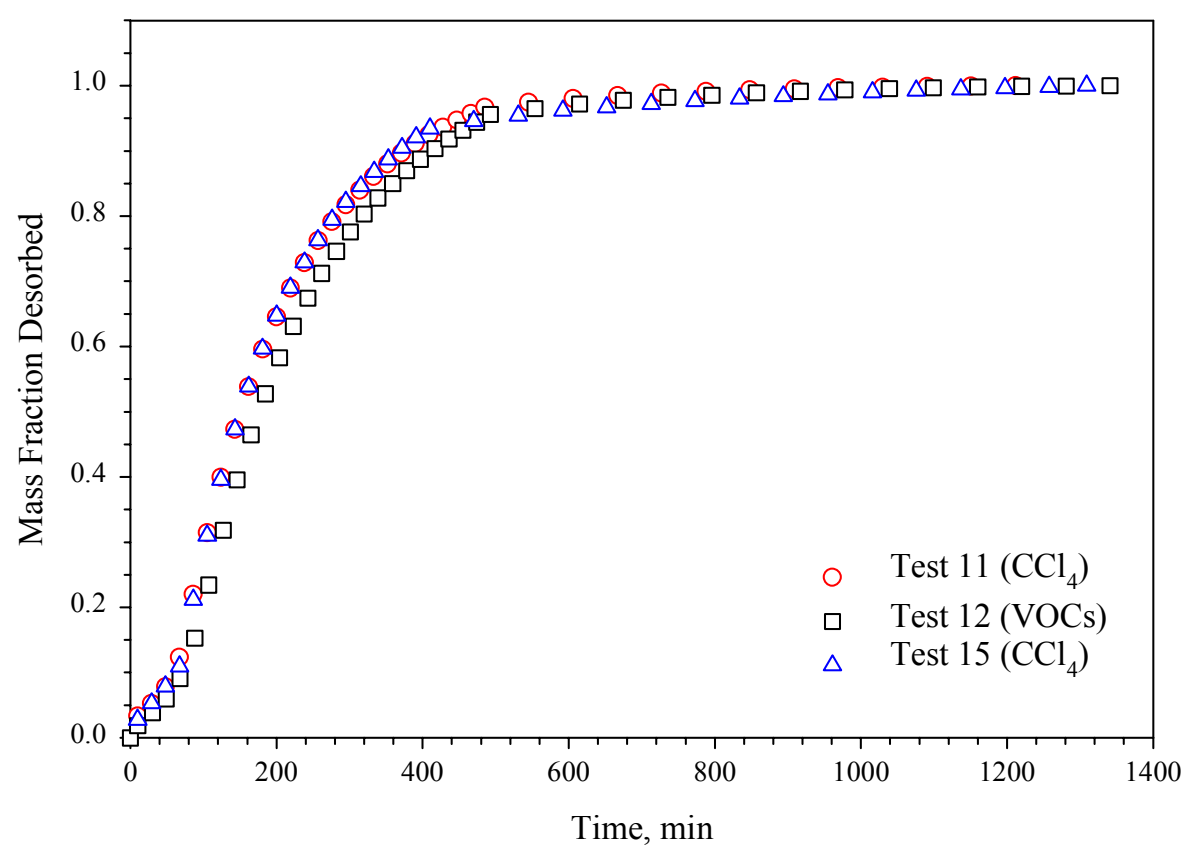

Figure 7. Comparison of thermal desorption tests conducted at a nominal 1-quart size utilizing sludge simulants containing all the VOCs (VOCs) vs. only carbon tetrachloride $\left(\mathrm{CCl}_{4}\right.$ 


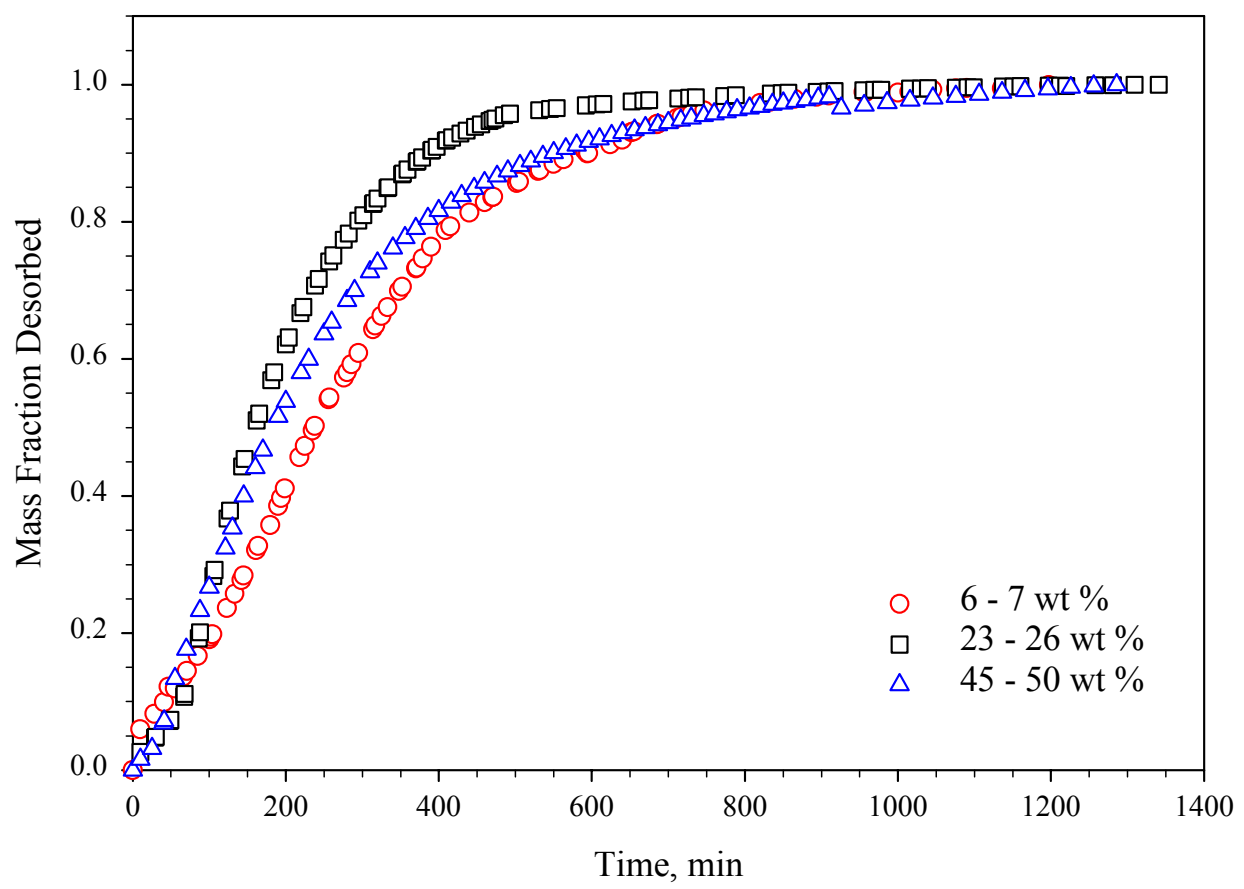

Figure 8. Effect of initial VOC concentration on thermal desorption rates.

To further evaluate this theory, it was decided to perform a 1-quart thermal desorption test on simulated IDC-003 sludge containing similar amounts of VOCs as the test condition containing 23-26 wt \% VOCs, but at substantially higher oil concentrations. The purpose of increasing the oil concentration (to $550 \mathrm{~g} / \mathrm{l}$ ) was to completely saturate or fill the pores in the surrogate sludge, without increasing VOC concentration in the sludge. The resulting thermal desorption profile from this single labscale test was then compared to the average thermal desorption profile for the "23-26 wt \% VOC, 1-quart" test condition $\left(80^{\circ} \mathrm{C}\right.$ thermal desorption temperature, 200 Torr applied pressure).

Figure 9 shows the effect of pore saturation level on VOC thermal desorption profiles. The results indicate that pore saturation exerts a significant influence on the rate of VOC desorption. This influence is more apparent when it is realized that only $68 \%$ of the VOCs were removed from the pore-saturated sludge, after $1446 \mathrm{~min}$, while $97-99 \%$ of the VOCs were removed from the unsaturated sludges, after only 1218-1391 min. Apparently, saturated (or filled) pores within the organic sludge can limit the effectiveness of the applied desorption pressure on VOCs within the sludge, lowering the overall rate of thermal desorption experienced. The data from Figure 8 is only less significant than the data from Figure 9 because the saturated pores in the "high VOC" tests are gradually becoming unsaturated, during the VOC desorption process.

The effect of pore saturation on vacuum-aided thermal desorption is only a factor for actual sludges that remain saturated, after many years of vented storage. Based on recent sampling evidence, the vented stored organic IDC-003 sludges at the INEEL are not expected to be saturated. 


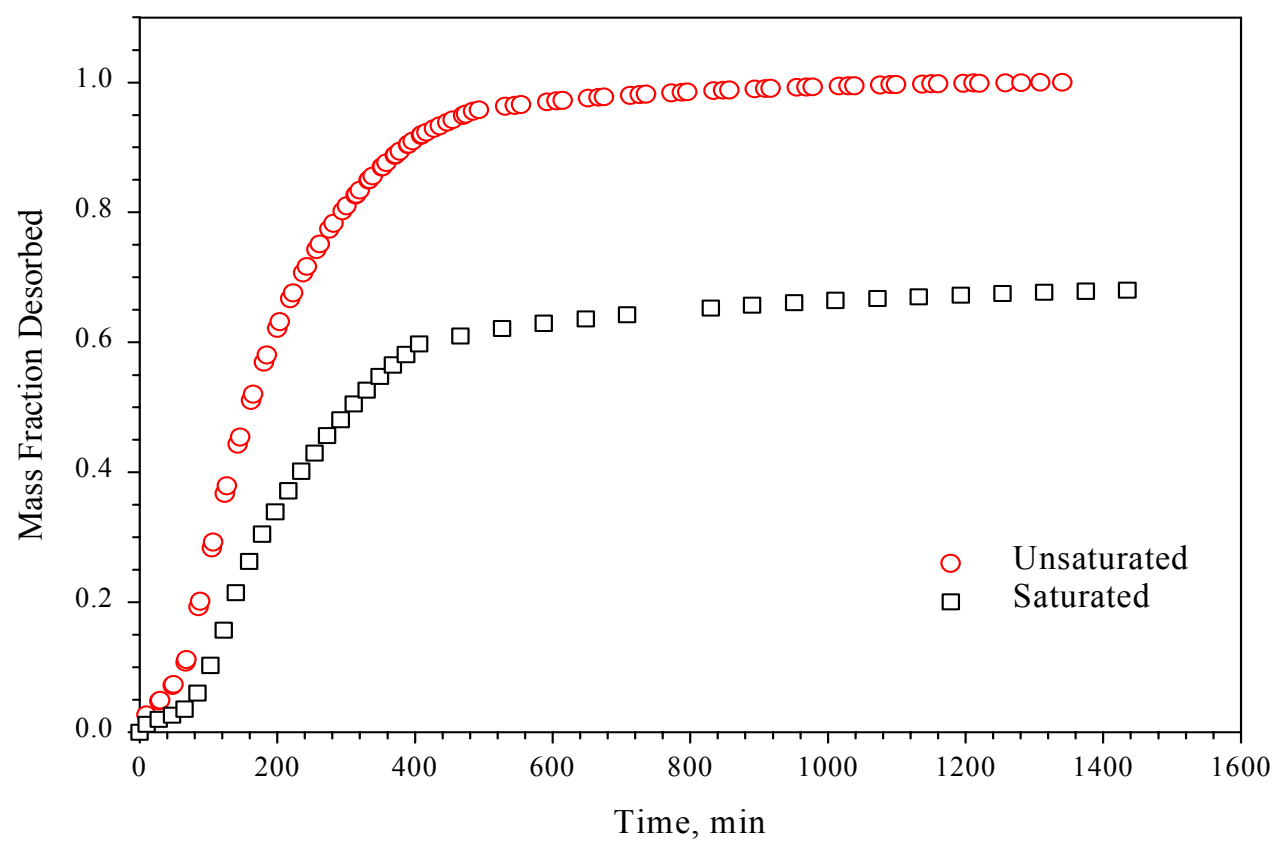

Figure 9. Effect of Pore Saturation on Thermal Desorption of VOCs.

As a final test condition comparison, the rates of thermal desorption were compared as a function of sludge volume. This was performed by comparing the average desorption rates for the three different volume test conditions containing less than $8 \mathrm{wt} \%$ initial VOCs (see Table 2). The effect of sludge volume on thermal desorption rates for lightly VOC-contaminated sludges is shown in Figure 10. As expected, Figure 10 shows that longer times are required to thermally desorb the contents of larger sludge volumes.

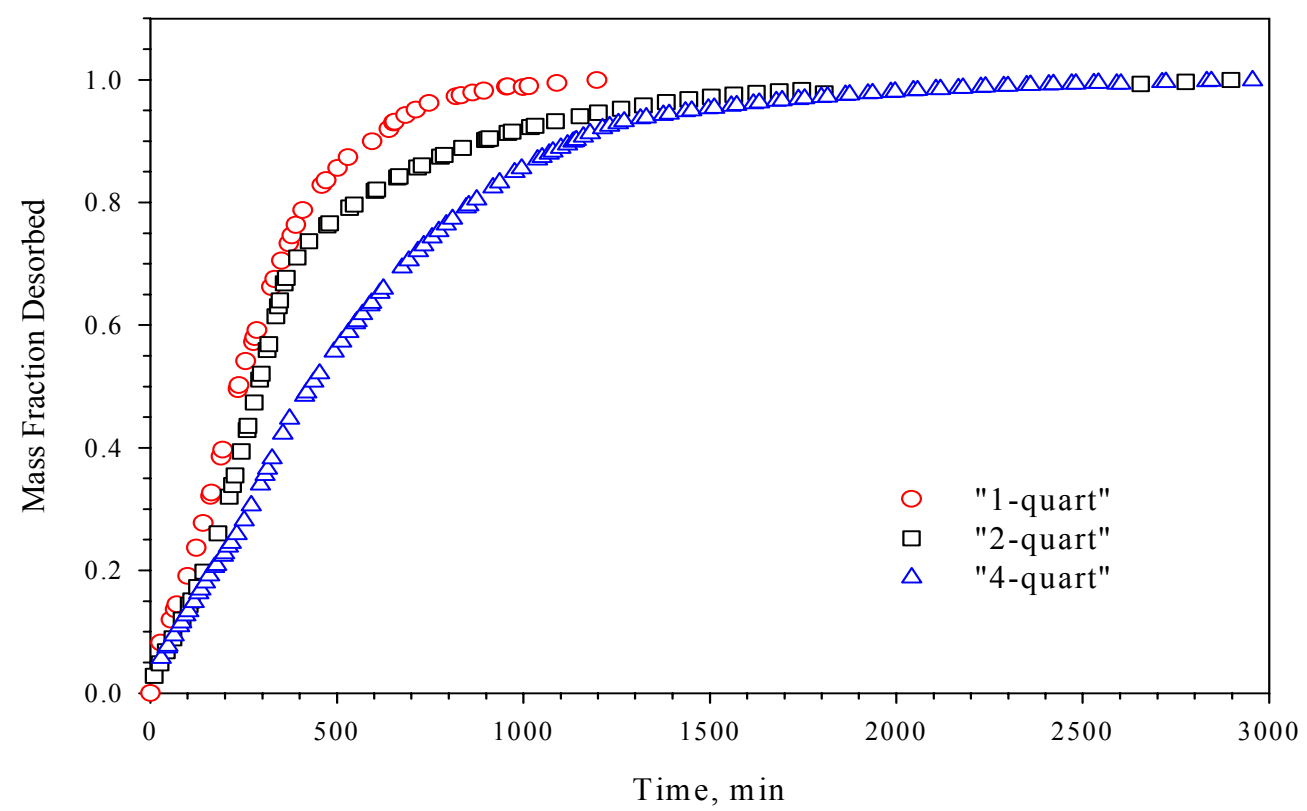

Figure 10. VOC Thermal Desorption Profile, As a Function of Sludge Volume. 


\subsection{Observed Temperature Gradients Within Simulated Sludge Samples at Various Test Conditions}

The purpose of measuring the temperature profiles within the different volumes of test sludge, under various test conditions was to obtain data that would be useful in the future development and validation of computational models for in-drum vacuum-aided thermal desorption processing. The development of a suitable model for the vacuum-aided thermal desorption treatment of organic sludges is beyond the scope of this study and will not be further discussed here. Due to the large number of temperature profiles obtained, and the repetitive nature of the data, only a representative portion of the temperature profile data that was obtained is discussed in this section. The entirety of the temperature profile data files, for all test conditions, is stored in the project files for this work. A summary of the complete data files is shown in Appendix A.

Information on the axial locations for each of the Type $\mathrm{K}$ thermocouple probes used in the thermal desorption tests is as previously described in Table 3 . The resulting temperature data (as a function of time, for each thermocouple location) provides illustrations of the axial and radial temperature profiles that were experienced in each sludge volume, during thermal desorption testing. The axially-oriented thermocouple probes that were used to monitor the simulant temperature contained five thermocouples evenly spaced along the length of the probe body. Each probe was placed at a selected radial position within the sludge (moving out from the centerline), with the probe tips placed approximately $1 / 8$-in. off the bottom inner surface of the sludge container. At the 1-quart and 2-quart nominal test volumes, the number four and five thermocouples of each axially oriented thermocouple probe were located above the top surface of the sludge (within the oven plenum). For the 4-quart nominal test volume, the number five thermocouple of each probe was the only thermocouple located above the top surface of the sludge (within the oven plenum). In all cases, the number one thermocouple in the axial probe tip is located near (albeit not touching) the bottom of the sludge container (as noted above).

Figures 11-13 show the resulting centerline, radial, and oven temperatures, vs. time (hereafter referred to as temperature profiles) experienced by a 1-quart simulated sludge that underwent a thermal desorption test at $80^{\circ} \mathrm{C}$ and 200 Torr applied pressure. From the examination of the TC-4 and TC-5 plots in Figures 11 and 12, it is clear that more rapid temperature rise relative to the other thermocouples is due to both of these thermocouples being located in the oven plenum. In the case of TC-1, the more rapid temperature rise (relative to TC-2 and TC-3) is due to the closer proximity of TC-1 to the oven heating elements, which are located beneath the floor of the vacuum oven. By examining the data presented in the Figure 13, it is evident that the oven temperature reaches a steady state condition in approximately 400 minutes. 


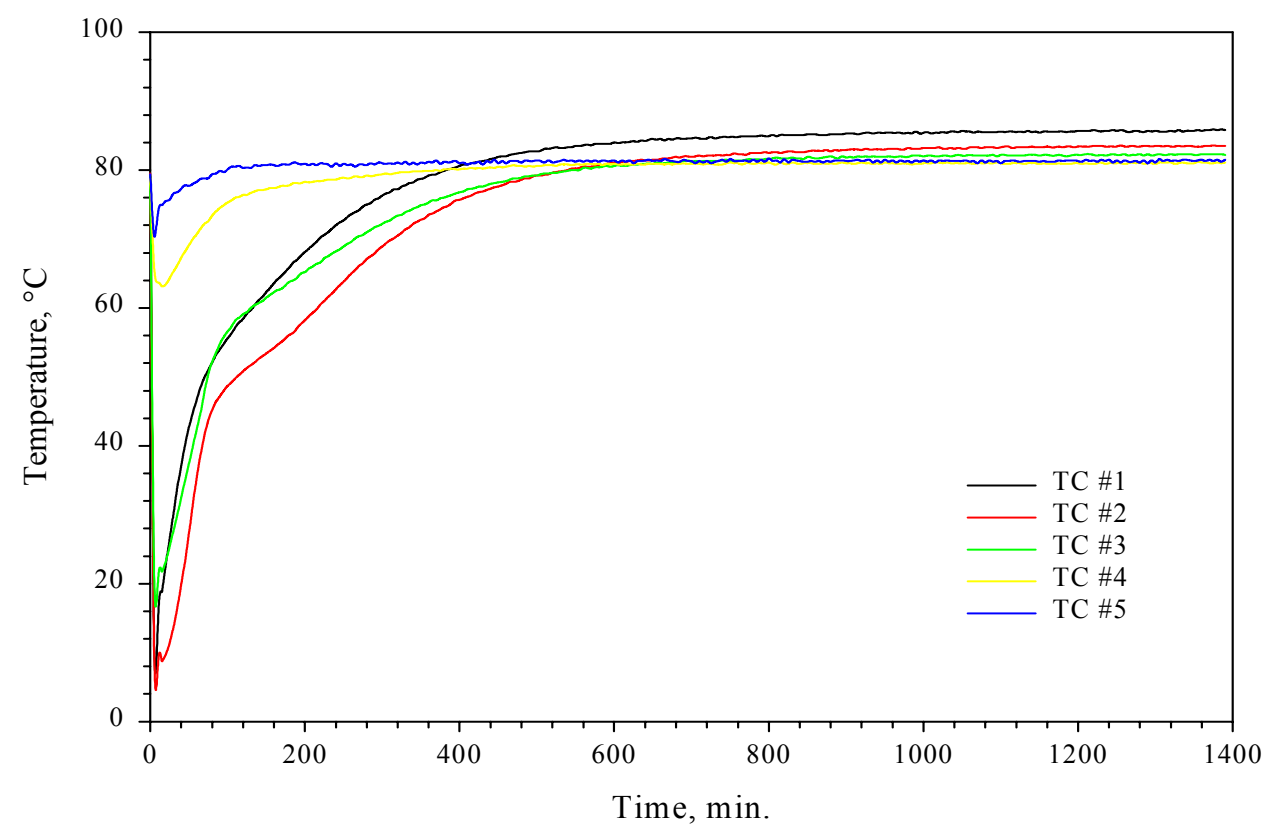

Figure 11. Centerline Temperature Profiles for a 1-qt Thermal Desorption Test $\left(80^{\circ} \mathrm{C}, 200\right.$ Torr).

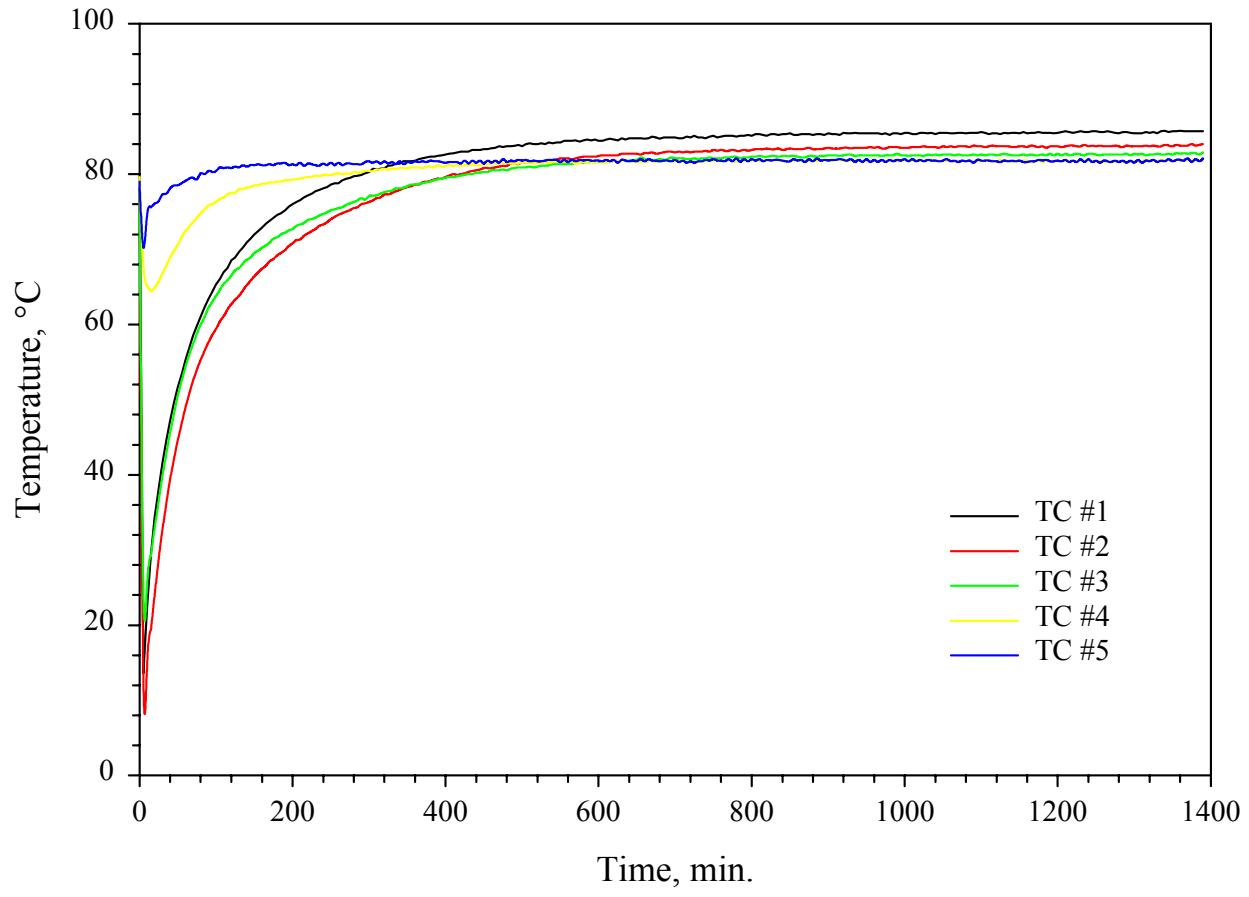

Figure 12. Radial Temperature Profiles for a 1-qt Thermal Desorption Test $\left(80^{\circ} \mathrm{C}, 200\right.$ Torr). 


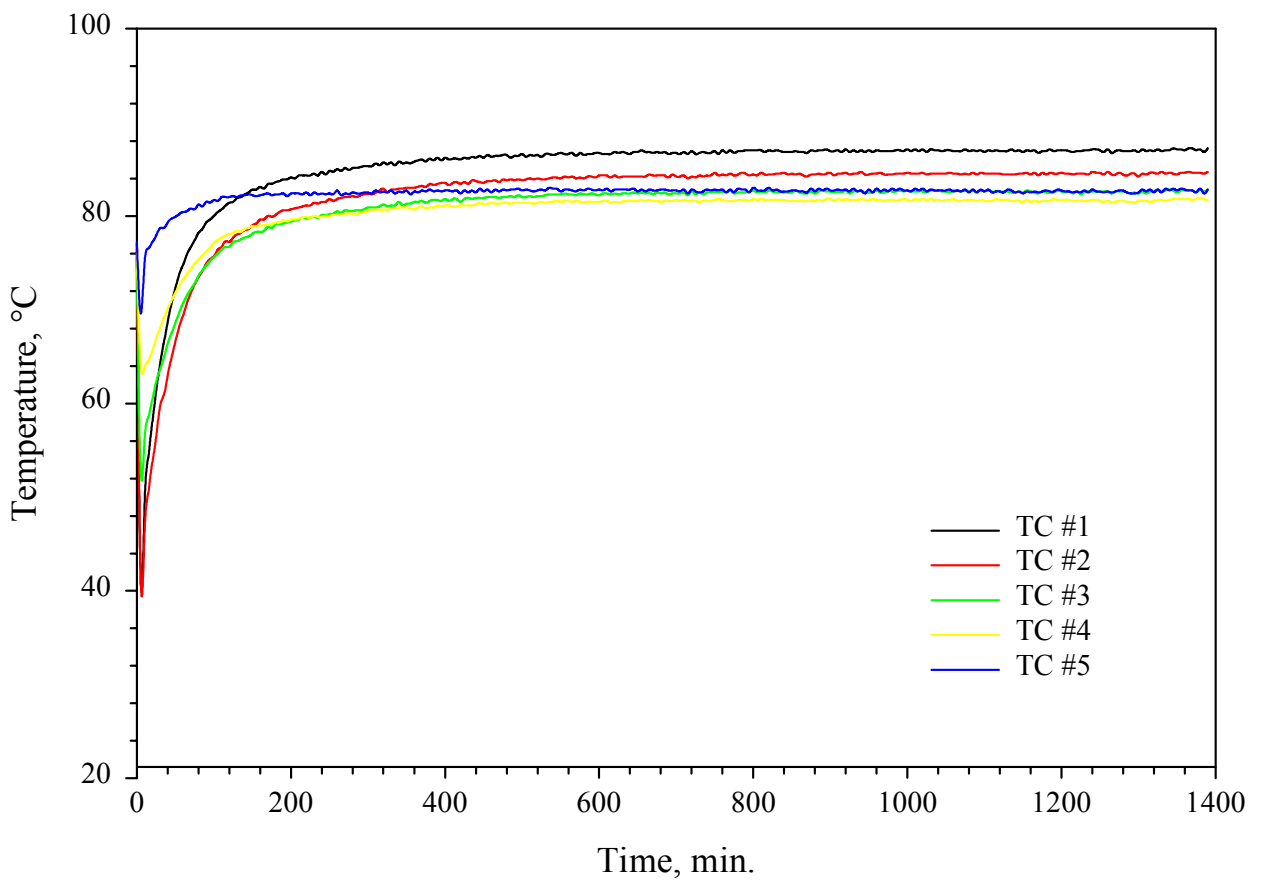

Figure 13. Oven Temperature Profiles for a 1-qt Thermal Desorption Test $\left(80^{\circ} \mathrm{C}, 200\right.$ Torr).

In contrast, approximately 600 and 800 minutes (See Figures 12 and 13) are required for the radial and centerline probe temperatures to reach a steady state condition, respectively. The observed lag times are consistent with the expected transient heat-up response for the sludge mass, when introduced into a constant-temperature heated environment, involving external heating of the sludge container by the oven.

The dependence of the average center-point temperature profiles for 1quart tests, as a function of initial VOC concentration, is shown in Figure 14. The center-point temperature profiles were averaged from the number 2 thermocouple in each of the center thermocouple probes, since they were closest to the center of each of the test sludges. As shown in Figure 14, the rate of temperature increase experienced by the center-point thermocouples in sludges containing high VOC concentrations appeared to be significantly depressed in the temperature range of $38-45^{\circ} \mathrm{C}$. A similar, albeit lesser, effect is observed in the temperature rise experienced by the test sludges containing moderate initial VOC concentrations. The reason for the observed depression in center-point temperature curves can be attributed to boiling of the bulk of the VOCs from the test sludges, between $38^{\circ} \mathrm{C}$ and $45^{\circ} \mathrm{C}$. At a pressure of 200 Torr, the boiling point for carbon tetrachloride (the predominant VOC in the test sludges) is $38^{\circ} \mathrm{C}$. For sludges containing significant volumes of VOCs, the constant rate of heat applied to the sludge, between $38^{\circ} \mathrm{C}$ and $45^{\circ} \mathrm{C}$ is being used to evaporate the VOCs, rather than raise the temperature of the sludge. This results in a depressed rate of heating, at temperatures between $38^{\circ} \mathrm{C}$ and $45^{\circ} \mathrm{C}$.

The dependence of the average center-point temperature profiles upon varying test volumes (each containing similar concentrations of VOCs) is presented in Figure 15. The center-point data for these curves generally involved the number 3 thermocouple in the centerline temperature probe, since this thermocouple has the slowest heat-up rate of all thermocouples present in each test sludge volume. As expected, the time required for the thermocouple to reach a steady state temperature increases as the size 


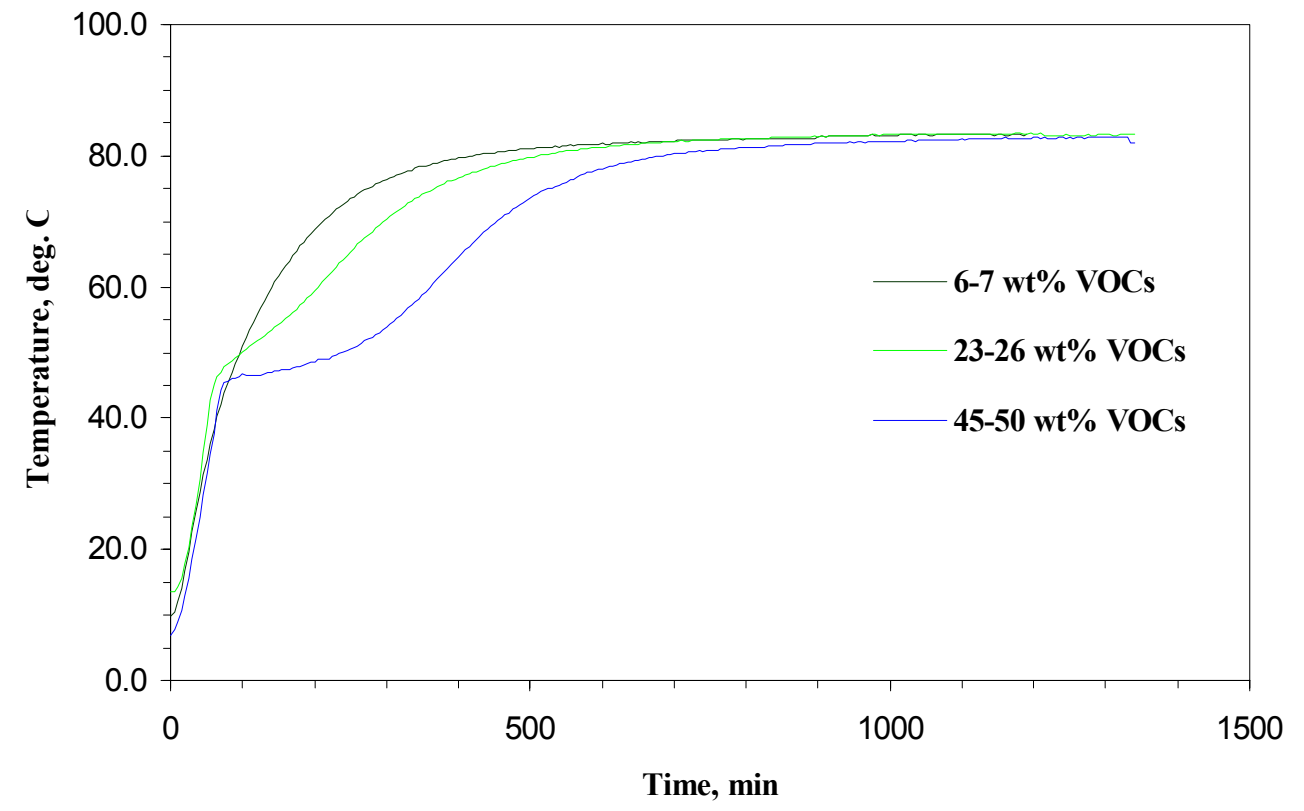

Figure 14. Comparison of center-point temperature profiles for 1-quart test volumes with low (6-7 wt $\%)$, medium (23-26 wt\%) and high (45-50 wt \%) VOC concentrations. Testing conditions: $80^{\circ} \mathrm{C}, 200$ Torr.

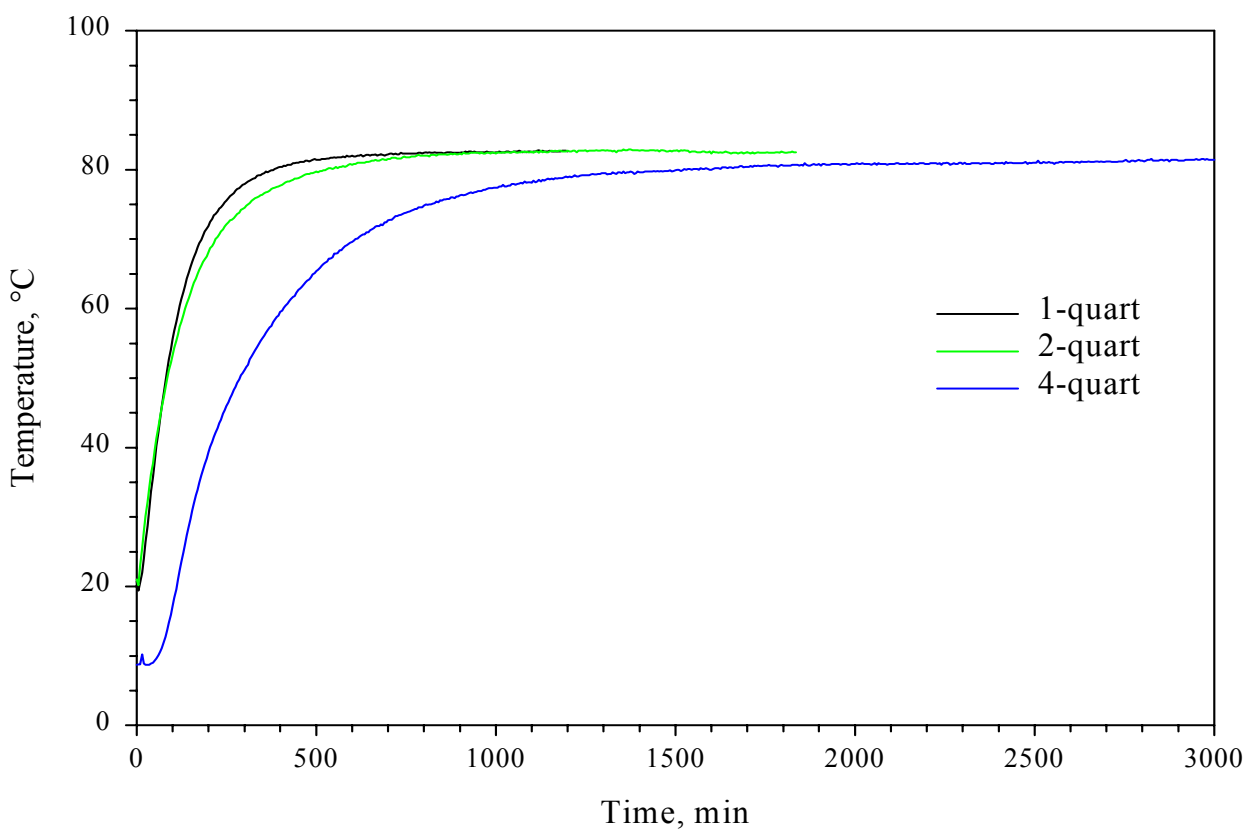

Figure 15. Comparison of centerline temperature profiles for 1-quart, 2-quart, and 4-quart nominal testing volumes containing approximately $10 \mathrm{wt} \%$ added VOC's. Testing conditions: $80{ }^{\circ} \mathrm{C}, 200$ Torr. 
of the sludge sample is increased. However, it is interesting to note that the 1-quart and 2-quart test volumes are relatively similar to each other, compared to the observed center-point temperature profile for the 4-quart test volume.

\subsection{Effective Mass Diffusion Coefficients for Thermally Desorbing VOCs, at Various Test Conditions}

Previous studies by other researchers indicated that the primary mechanism expected to influence rates of VOC evaporation from IDC-003 organic sludges, at ambient conditions $\left(25^{\circ} \mathrm{C}, \sim 700\right.$ Torr $)$, could be ascribed to a binary liquid diffusion mode ${ }^{10}$. The studies also suggested that the absorbent matrix within the sludge does not influence VOC desorption rates significantly ${ }^{10}$. Although our data indicates that pore saturation significantly influences vacuum-aided thermal desorption rates, utilizing the binary liquid model can provide a useful comparison of our test data to that from previous studies at ambient conditions. In particular, estimates of the average and time-dependant mass diffusivities from our tests at reduced pressure can be compared with effective mass diffusivities from previous tests at ambient conditions, to contrast how the various test conditions may influence and enhance vacuum-aided thermal desorption of VOCs from the sludge matrix.

Since our lab-scale tests involved VOC desorption out of the top of cylindrical containers of various diameters, the binary diffusion model for a slab was used. According to Incropera and DeWitt ${ }^{11}$, the relationship between mass diffusivity and concentration is given by the following partial differential equation:

$$
\frac{\partial \mathrm{C}}{\partial \mathrm{t}}=\mathrm{D} \frac{\partial^{2} \mathrm{C}}{\partial \mathrm{z}^{2}}
$$

where $\quad \mathrm{C}=$ concentration;

$\mathrm{t}=$ time;

$\mathrm{D}=$ the mass diffusion coefficient; and

$\mathrm{z}=$ the axial position within a slab of thickness L.

Solving this equation, with substitution of the appropriate constants, results in the following expression:

$$
C_{\text {avg }}=\frac{8 \mathrm{C}_{0}}{\pi^{2}} \sum_{n=1}^{\infty} \frac{1}{(2 n+1)^{2}} \cdot \mathrm{e}^{\frac{-D(2 n+1)^{2} \pi^{2} t}{4 L^{2}}}
$$

where $\quad \mathrm{C}_{\mathrm{avg}}=$ the average VOC concentration in the oil;

$\mathrm{C}_{\mathrm{o}}=$ the initial VOC concentration in the oil; and

$\mathrm{L}=$ the height of the liquid layer.

Using a previously derived numerical simulation of this solution, the effective mass diffusion coefficients were calculated for each of the lab-scale thermal desorption tests that were performed. Table 5 shows the calculated mass diffusion coefficients, as a function of test condition. 
Table 5. Calculated Average Mass Diffusion Coefficients for Each Lab-Scale Test Condition $\left(80^{\circ} \mathrm{C}, 26-30 \mathrm{kPa}\right)$.

Test Conditions

\begin{tabular}{cc}
\hline $45-50 \%$ VOCs, $740 \mathrm{ml}$ (sat) & $1.14 \mathrm{E}-03 \mathrm{~cm}^{2} / \mathrm{s}$ \\
$23-26 \%$ VOCs, $715-735 \mathrm{ml}$ (unsat) & $1.01 \mathrm{E}-03 \mathrm{~cm}^{2} / \mathrm{s}$ \\
$6-7 \%$ VOCs, $815-835 \mathrm{ml}$ (unsat) & $7.31 \mathrm{E}-04 \mathrm{~cm}^{2} / \mathrm{s}$ \\
$7-8 \%$ VOCs, $1670-1720 \mathrm{ml}$ (unsat) & $8.71 \mathrm{E}-04 \mathrm{~cm}^{2} / \mathrm{s}$ \\
$7-8 \%$ VOCs, $3130 \mathrm{ml}$ (unsat) & $6.91 \mathrm{E}-04 \mathrm{~cm}^{2} / \mathrm{s}$ \\
$21 \%$ VOCs, $816 \mathrm{ml}$ (sat) & $6.75 \mathrm{E}-04 \mathrm{~cm}^{2} / \mathrm{s}$ \\
\hline
\end{tabular}

Upon reviewing the calculated mass diffusion coefficients for each test condition, it appears that initial VOC concentration may influence the effective mass diffusion coefficients expected from vacuum-aided thermal desorption. This is contrary to existing-diffusion theory. However, in comparing the measured VOC desorption profiles with those modeled from the calculated mass diffusion coefficients, it appears that the calculated diffusion coefficients only provide representation for an average diffusion rate, over the entire desorption period. They do not effectively model diffusion rates, vs. time, over the entire period of desorption.

An example of this is shown in Figure 16, which compares the measured thermal desorption profiles with modeled desorption profiles (based on a calculated mass diffusion coefficient) for a 4-quart unsaturated sludge test, containing 7-8 wt \% VOCs. Figure 16 shows that the initial rates of thermal desorption are substantially less than that predicted by the calculated mass diffusion coefficient.

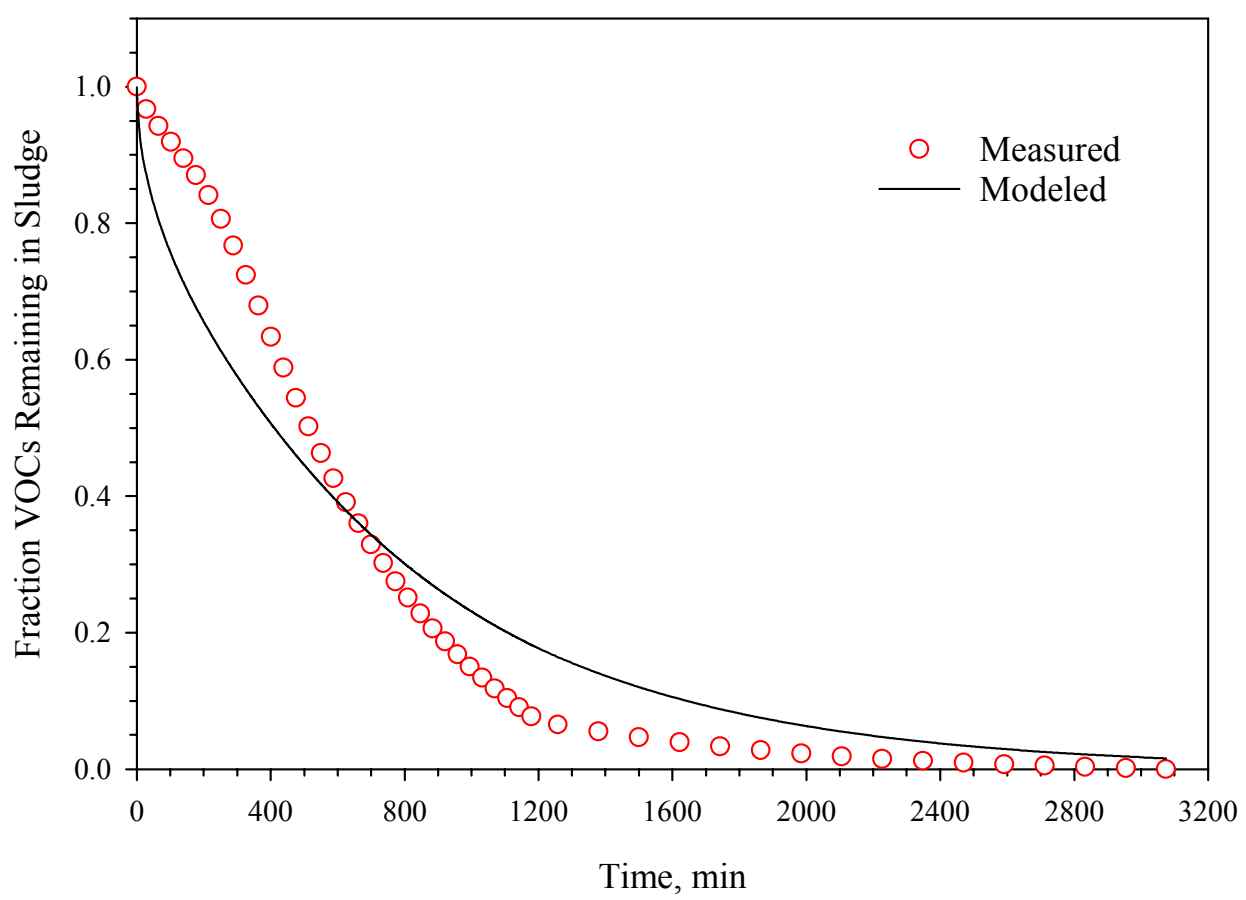

Figure 16. Measured vs. Modeled VOC Desorption Profile for a 4-quart, Unsaturated Sludge, Containing $7-8$ wt \% VOCs. 
However, the measured rate eventually increases to a level substantially greater than predicted by the calculated effective mass diffusion coefficient. Similar conclusions were reached for the other labscale test conditions. The evaluation of the desorption profile shows that the actual mass diffusion coefficient associated with vacuum-aided thermal desorption is not constant during thermal desorption.

An attempt was made to determine the time-dependent mass diffusion coefficient profile for each thermal desorption test, based on measured desorption profiles, vs. time. This approach was relatively successful for sludge simulations with volumes less than approximately 1-quart, but unsuccessful at greater volumes. The reason for this is attributed to the more pronounced transient temperature gradients produced in the large volume tests. In essence since mass diffusion coefficients are a function of temperature, the sludge tests with larger volumes have larger temperature gradients that limit the ability to accurately model thermal desorption behavior, using a constant bulk mass diffusion coefficient. The results support a recommendation to develop a computational finite-element based model to account for spatial variations in temperature dependent properties for mass diffusion, and other transport mechanisms (micro-boiling and vapor transport). The model would support effective design/development of a fullscale, in-drum, vacuum-aided thermal desorption system and process control methods.

Results of the time-dependent mass diffusion coefficient profile evaluation for small sludge volumes indicate that mass diffusion coefficients are initially below $1 \mathrm{E}-05 \mathrm{~cm}^{2} / \mathrm{s}$. However, the mass diffusion coefficient eventually reaches levels of 7.7 E- 04 to $1.5 \mathrm{E}-03 \mathrm{~cm}^{2} / \mathrm{s}$. Such peak mass diffusion coefficients, determined for the small-volume tests are 90-180 times greater than the predicted mass diffusion coefficients for $\mathrm{CCl}_{4}$ at $80^{\circ} \mathrm{C}$, using either the modified Darken or Vignes correlations ${ }^{12}$, which estimated the mass diffusion coefficient to be approximately $8 \mathrm{E}-06 \mathrm{~cm}^{2} / \mathrm{s}$.

Although the calculated mass diffusion rates are substantially higher than predicted according to theory, they are consistent with ongoing concurrent university lab studies attempting to predict the binary mass diffusion coefficient for $\mathrm{CCl}_{4}$ from Regal oil, at elevated temperatures and reduced pressures. The primary reason for the substantially higher effective mass diffusion coefficients, during vacuum-aided thermal desorption, is the occurrence of micro boiling of the VOCs in the organic liquid. Micro boiling may be causing the VOCs to thermally desorb from the oil at a rate substantially faster than predicted by a binary-liquid mass diffusion theory-based model. This is not surprising, since vapor bubble mass transport rates in a liquid (along with the subsequent release from the surface) would be expected to be several orders of magnitude higher than simple liquid diffusion rates. The increased rate of mass diffusion is analogous to the increased magnitude in energy transport (several orders of magnitude) experienced by boiling heat transfer, compared to conductive (energy diffusion) heat transfer rates in a liquid. The results support the conclusion that vacuum-aided thermal desorption can significantly enhance the release of VOCs from an organic sludge waste matrix.

Applying the binary liquid diffusion model to estimate effective "time-dependent" mass diffusion coefficients is also useful in further evaluations pertaining to the effect of pore saturation on reduced diffusion rates from the oil-saturated sludge (see Figure 9). The initial effective mass diffusivity of the oil-saturated sludge was $2.6 \times 10^{-5} \mathrm{~cm}^{2} / \mathrm{s}$, during the first 65 minutes of thermal desorption (approximately 3 times higher than that predicted by the modified Darken or Vignes calculations, for binary liquid diffusion with surface evaporation). Eventually, the oil-saturated sludge experienced peak mass diffusion rates of over $1.1 \times 10^{-3} \mathrm{~cm}^{2} / \mathrm{s}$ (approx. 140 times higher than rates predicted by the modified Darken or Vignes calculations). However, after 400 minutes of relatively rapid thermal desorption, the oil-saturated sludge dropped to an effective mass diffusion rate between $1 \times 10^{-6} \mathrm{~cm}^{2} / \mathrm{s}$ and $5 \times 10^{-5} \mathrm{~cm}^{2} / \mathrm{s}$ (equivalent to that predicted by the modified Darken or Vignes calculations).

Figure 17 shows the measured mass desorption profile for the oil-saturated sludge test, vs. modeled thermal desorption profiles, using both constant and varied mass diffusion coefficients (different constant 
values for each of the three time periods noted). The figure shows the improved comparison when modeling the mass desorption profile with a time varying mass diffusion coefficient.

The likely phenomena experienced by the oil-saturated sludge may help explain the different desorption rate periods and influence of saturated pores. During the initial constant stage (first 65 minutes), the sludge is being heated from room temperature to a temperature sufficient (in combination with applied vacuum pressure) to cause the VOCs within the sludge to locally boil (greater than 38C at 200 torr) and lead to vapor mass desorption rates higher than predicted for liquid-liquid mass diffusion. This should occur rapidly for the near surface sludge regions, but will lag for the inner regions of the sludge, consistent with the constant boundary temperature heating transient. The VOCs in the near surface region also directly and immediately experience the applied vacuum pressure (lower localized pressure) leading to a lower saturation temperature for onset of local boiling, while the lower regions see slightly higher local pressures and saturation temperatures as a result of the gravity head of sludge/liquid. For most sludges that contain high quantities of VOCs (relative to oil), the rapid rate of micro-boiling thermal desorption stays generally constant through the remainder of the test. This is because the thermally desorbing sludge is becoming more and more porous over time (essentially lowering the effective top surface for vapor release from the remaining liquid/sludge and increasing the influence of applied vacuum on VOC regions present at the bottom of the container). However, for the oil-saturated sludge, desorption of VOCs from the sludge does not appear to increase the relative porosity of the thermally desorbed sludge over time. Rather, the oil remains in the pore spaces of the sludge, limiting open porosity. The oil present within the saturated sludge pore spaces maintains an effective vertical pressure gradient and also the effective distance to the vapor release surface. Based on existing data from the singular test involving oil-saturated sludge, it appears that the resulting pressure drop, within the saturated-sludge, is sufficient to eliminate significant micro boiling, at the localized temperatures and

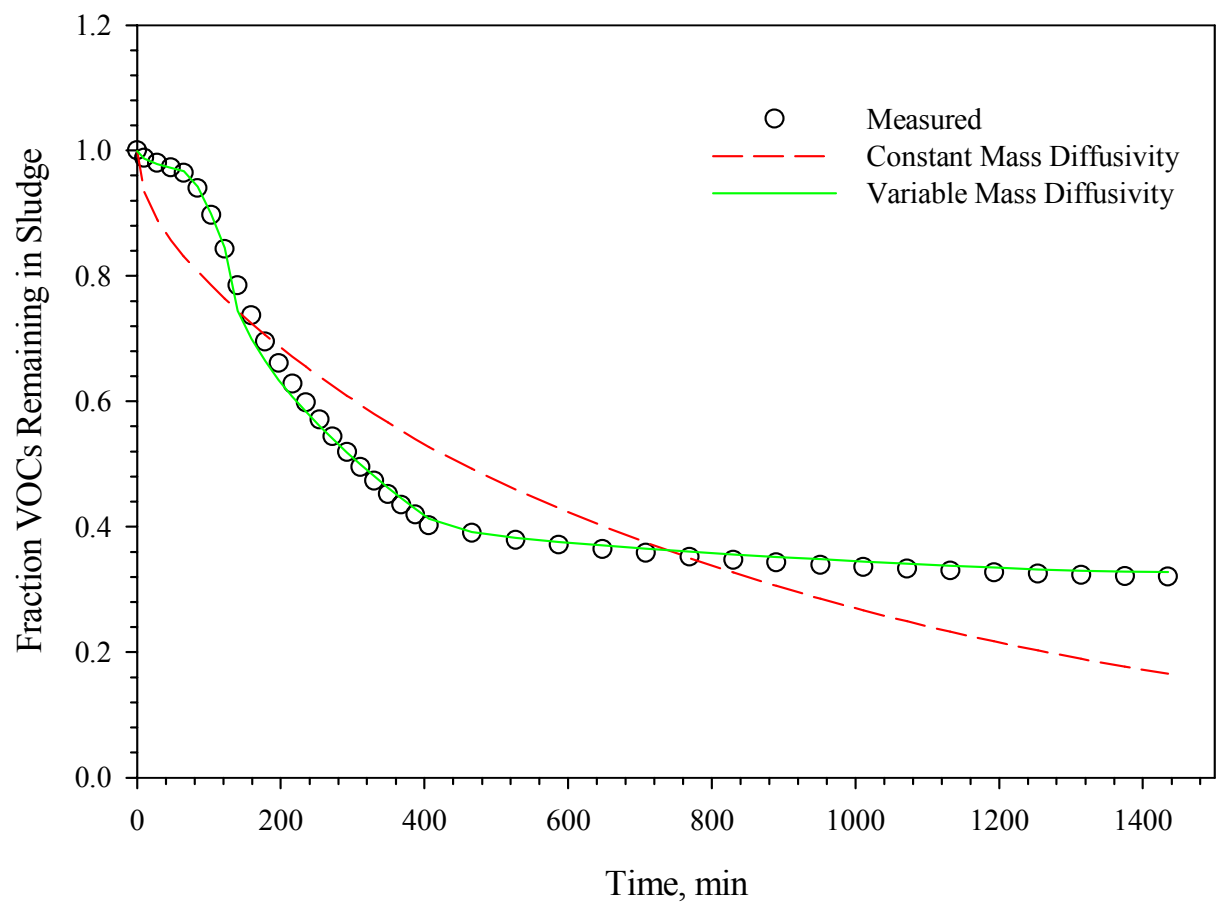

Figure 17. Comparison of Measured Mass Desorption Profile with Modeled Mass Desorption Profiles, Using Constant and Varying Effective Mass Diffusivities (1-quart, Oil-Saturated Sludge, 21 wt\% VOCs) 
pressure conditions present near the bottom of the sludge. When this occurs, the rate of thermal desorption returns to a level essentially consistent with that expected for liquid diffusion and evaporation from a surface (i.e., rates dominated by liquid mass diffusion transport in the bulk liquid).

While fundamentally important, the phenomena of sludge pore saturation (oil/voc liquid filled pores) limiting the rates of vacuum-aided thermal desorption may not necessarily affect many of the IDC-003 sludges (organic setups) or the similar RFP series 700/801 solidified/cemented organics. This is because many of the stored drums of these sludges are now likely relatively porous, or unsaturated, since many of the original VOCs present in the original sludge will have already evaporated following much earlier drum venting at time of retrieval. The effect will, however, still be important to consider for newly vented sludge drums, and possibly for solidified/cemented sludges (700/801's) which may have a less porous more flow resistant solidified matrix. It could also potentially affect vacuum thermal desorption behavior from lower regions of sludges in full scale drums if the remaining oil and oil/voc mixture coalesces/pools in the drum bottom. The small scale test results support further evaluation of this affect in larger-scale thermal desorption systems and with appropriate computational models, since the distance and potential pressure drop (flow resistance) are substantially greater in full-scale drums. It is also likely that a variety of conditions will be experienced during a desorption process. Therefore, it is recommended that this phenomenon be further evaluated for both simulated IDC-003 and Series 801 OASIS sludges via both specially designed small-scale tests, aimed at supporting the computer modeling effort, and as part of the anticipated full-scale thermal desorption system testing effort.

\section{CONCLUSIONS AND RECOMMENDATIONS}

Based upon the initial exploratory test data and limited results evaluations described in the previous section the following primary conclusions and recommendations are provided.

It is clear that application of a reduced pressure boundary condition could significantly enhance the rates of thermal desorption from a sorbed/solidified liquid organic/oil "sludge" waste, while maintaining a selected temperature condition sufficiently low to prevent destruction of the waste drum packaging materials (confinement) surrounding the waste. The concept of an in-drum thermal desorption process, therefore, has considerable merit and additional development work should be pursued.

The results indicate that controlling mechanisms and VOC release behavior/rates in the vacuum thermal desorption process cannot be adequately represented with a simple bulk liquid-liquid concentration driven mass-diffusion model. This is because the overall mass release rates observed in these tests were generally two orders of magnitude greater than predicted by simple concentration driven liquid-liquid mass diffusion. This difference can be partially attributed to the effects of the transient temperature distribution/gradients on diffusion within the sludge during heat-up. However, it is thought to be primarily due to micro boiling of the volatile organics within the simulated sludge. This micro boiling occurs as the localized temperatures exceed that required for boiling of the VOCs from the sludge, under vacuum-aided thermal desorption conditions.

The results also indicate that the available porosity and pore saturation conditions in the simulated sludge matrix can significantly influence the desorption rates, along with the size/volume of the sludge mass, and the initial VOC/oil mixture concentrations. It appears that the observed effects of the various parameter changes on VOC thermal desorption rates can all be related back to their influence upon whether or not the localized temperature and pressure condition, within an organic sludge, exceeds the VOC saturation vapor conditions at that location. If so, this would be expected to induce local VOC boiling/vapor production in that local region and lead to a two-phase, vapor-driven transport condition. This would then lead to VOC mass release rates several orders of magnitude higher than that experienced by simple liquid-liquid diffusion. 
The above results and conclusions suggest that two primary VOC transport controlling conditions or mechanisms exist simultaneously, for different regions of the sludge, and that these regions change over time as the thermal transient moves to steady state. In regions where the local temperature is lower than that required for VOC boiling (at the local pressure), the primary mass transport mechanism is likely liquid-liquid diffusion to an evaporating surface. In regions where the local temperature is higher than that required for VOC boiling (at the local pressure), micro boiling and attendant vapor transport through liquid to an open surface for vapor release is likely the dominant transport mechanism. Support for this theory is based on the previously discussed results and following summary observations from the tests:

- The test conditions clearly involved transient heat-up of the sludge matrix, with attendant temperature gradients.

- The driving temperature/energy was essentially from a controlled temperature, convective surface boundary temperature condition (with the exception of a partial local conduction driven boundary condition at the bottom of the container), as noted by the temperature profiles. ${ }^{a}$

- The times at which a given local mass region of the simulated sludge achieved local temperature conditions matching/exceeding VOC saturation temperature sufficient for micro-boiling vapor generation were clearly different, and in some cases a portion of the sludge may never have entered the local boiling condition.

The eventual steady state temperature condition experienced by the sludge is also clearly important, since both controlling transport mechanisms may still exist for some portions of the sludge, at that point. However, this is dependent upon the temperature and pressure around a localized region, the operating temperature/pressure applied to the sludge and the surrounding pressure drop across the sludge matrix (between the localized zone and the effective free release surface). The configuration of open porosity in the solid matrix and whether it is or is not filled with oil depleted of VOCs at that point would therefore be expected to influence the situation.

The results suggest a need for developing a more sophisticated finite element based computational model to better represent and understand the spatially dependent and coupled transient heat and mass transport conditions occurring in the application of vacuum thermal desorption conditions to an organic sludge matrix. The model must be able to regionally predict heat and mass transport, including appropriate boundary conditions and spatially dependent transient temperatures and pressures, and utilize materials properties reflecting the local temperature and pressure conditions. The model must include methods to represent both postulated dominant mass transport mechanisms in appropriate regions and times, i.e. the local VOC boiling vapor generation and vapor transport through the liquid/sludge matrix and also the liquid in liquid mass diffusion transport to evaporative surface conditions. The modeling effort needs to be supported with further controlled parameter testing, at both small and (eventually) fullscale conditions. The resulting model would support effective design and optimization of a full-scale, indrum, vacuum-aided thermal desorption system and process control methods.

a. The driving temperature/energy is consistent with the setup or placement of the small sludge containers on the bottom of the convection oven with an external bottom surface heater. 
The existing time dependent thermal temperature profile and mass loss data obtained from these tests provides a reasonable starting point for initiating the next step in developing and verifying more sophisticated computational models. These models are needed to predict the transient thermal response and coupled mass release determinations from an organic sludge matrix, as a function of various vacuumaided thermal-desorption conditions. Although the problem is clearly a coupled transient and spatially dependent heat and mass flow/transport problem, an initial step could be to develop two independent, but loosely coupled models:

- A spatially-dependent, two-dimensional transient heat transfer model (including the effect of the regional/local VOC phase transition on energy transport and temperature) and

- A separate one dimensional flow model (or models) reflecting the appropriate physical matrix flow path configuration conditions (open vs. filled or closed porosity) and controlling mechanisms (liquid-liquid diffusion or gas/vapor diffusion from a liquid).

The above could initially utilize existing models for liquid-liquid mass diffusion and for boiling/vapor transport out of liquids with appropriate approximations for materials properties available from the literature. The resulting models could then be evaluated and improved through subsequent labscale tests, under controlled conditions.

It should be noted that the studies to date have focused primarily upon evaluating the desorption/transport of VOCs from organic sludges consisting of oil/VOC liquid organic that has been sorbed/setup into a sludge/solid using a calcium silicate sorbent. The resulting calcium silicate organic sludge (organic setups) may very well have higher open porosity than other, cemented/solidified organic waste streams (such as IDC-004 sludges and Series 801 OASIS sludges). These exploratory tests results have indicated that amount of open versus filled sorbent porosity can significantly influence the rate of desorption through pressure gradient affects on local pressure (affecting boiling vapor transport versus liquid-liquid transport) and attendant mass flow resistance (pressure drop). As a result, some predictive modeling and testing is needed to address potential differences in vacuum thermal desorption behavior for other organic sludge matrices that may have less open porosity e.g., calcium sulfate cemented organic wastes.

With actual drums of organic sludge, the removal of VOCs from the sludge must account for the release of vapors through the accompanying waste packaging, as well as the sludge. This packaging includes the plastic over-pack and/or bagging surrounding the organic sludge wastes, as well as any HEPA-filterd vents that are present in each drum. Existing one-dimensional models could be utilized to obtain an initial approximation of whether the confinement layers resistance will be a significant or potentially dominant factor on the effective rates of gas/vapor release from the drum and potential practical processing rates. Consideration should also be given towards the evaluation of hydrogen gas transport through the waste packaging materials. Initial full-scale studies examining vacuum thermal desorption of organic sludge vapors/gases through appropriately packaged waste drum surrogates, should also be performed. It should be noted, however, that rather simple physical/mechanical approaches for breaching the inner bag confinement layers are also possible, if found necessary to increase effective release rates from the drum of vapors/gases desorbed from the sludge matrix.

Lastly, it should be noted that it is possible to further reduce the driving boundary condition pressures with additional vacuum capability and clearly drive the entire sludge matrix into a steady state VOC boiling condition, if necessary to assure effective matrix desorption rates and complete desorption of all organic materials. It might be possible to achieve such a condition, under high vacuum-aided conditions. This could potentially desorb suspect poly-chlorinated biphenyls (PCBs) that may be present in the 
organic sludge (along with the entire oil matrix if necessary). However, it is not clear that any of these conditions will be needed. Therefore, they are not a focus of current studies.

In summary, a final determination of the effectiveness of vacuum-aided thermal desorption cannot be made, based on this limited set of exploratory tests. It is clearly promising, however, and should be evaluated further through a combination of additional computational modeling, small scale controlled parameter tests, and full-drum scale surrogate testing. 


\section{REFERENCES}

1. U.S. DEPARTMENT OF ENERGY. Report of the Secretary of Energy Advisory Board's Panel on Emerging Technological Alternatives to Incineration. U. S. Department of Energy, Washington, DC (December, 2000).

2. G.L. GROVER. Presentation to the 2001 TRUPACTIII Gas Generation Testing Program Meeting, Albuquerque, NM (October30, 2001).

3. R.H. PERRY and C.H. CHILTON. Chemical Engineers' Handbook. $5^{\text {th }}$ Edition, Table 3-8, pp. 349 to 3-60, McGraw-Hill, Inc. (1973).

4. M.W. COOK, D.N. HANSON, and J.B. ALDER. "Solubility of Hydrogen and Deuterium in Nonpolar Solvents". Journal of Chemical Physics, Vol. 26, No. 1, pp. 748-751 (April, 1957).

5. R.H. PERRY and C.H. CHILTON. Chemical Engineers' Handbook. $5^{\text {th }}$ Edition, Tables 23-10 \& 23-13, pp. 23-62 to 23-63, \& 23-66, McGraw-Hill, Inc. (1973).

6. R. K. FARNSWORTH. Private communication with S. Kirkham, November 2001.

7. WASTREN, INC. Acceptable Knowledge Document for INEEL Stored Transuranic Waste-Rocky Flats Plant Waste. INEL-96/0280, Rev. 2. Idaho National Engineering Laboratory, Idaho Falls, ID, 83415 (1998).

8. DAVID L. BARBER, KEVIN P. CARNEY, AND JACK C. DEMIRGIAN. Batch Experiment Investigation of Hydrogen Content in IDC-003 Sludge. Argonne National Laboratory. DOE Transuranic Mixed Focus Area website (http://tmfa.inel.gov/Documents/ BatchE.pdf) (October 22, 2001).

9. ERIC C. MILLER and MARK D. VARVEL. Reconstructing the Past Disposal of 743-Series Waste in the Subsurface Disposal Area for Operable Unit 7-08, Organic Contamination in the Vadose Zone. INEEL/EXT-01-00034, Rev. 0, Idaho National Engineering and Environmental Laboratory, Idaho Falls, ID 83415, (2001).

10. ERIC C. MILLER. Carbon Tetrachloride Mass Transfer from a Clay Mineral Absorbent/Petroleum Oil Waste Form: Mechanisms and Rates. Masters of Science Thesis, Waste Management and Environmental Science, Idaho State University (1999).

11. F.P. INCROPERA and D.P. DEWITT. Fundamentals of Heat Mass Transfer, $4^{\text {th }}$ ed. John Wiley and Sons, Inc., New York (1996).

12. R.C. REID, J.M. PRAUSNITZ, and B.E. POLING. The Properties of Gases and Liquids, $4^{\text {th }}$ Ed. McGraw Hill, Boston (1987). 


\section{Appendix A \\ Sludge Project Run Information}




\begin{tabular}{|c|c|c|c|c|c|c|c|c|c|c|c|c|c|c|}
\hline & 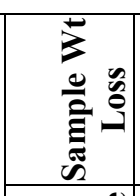 & & & 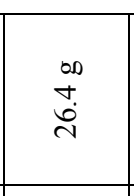 & $\overleftrightarrow{Z}$ & 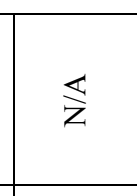 & $\overleftrightarrow{Z}$ & $\begin{array}{l}{ }^{\infty} \\
\text { के }\end{array}$ & & $\overleftrightarrow{\mathrm{z}}$ & & $\overleftrightarrow{Z}$ & \\
\hline & & 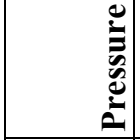 & $\begin{array}{l}5 \\
0 \\
0 \\
8 \\
0\end{array}$ & $\begin{array}{l}5 \\
0 \\
0 \\
8 \\
0 \\
n\end{array}$ & $\begin{array}{l}1 \\
0 \\
0 \\
0 \\
0 \\
0\end{array}$ & $\begin{array}{l}5 \\
0 \\
0 \\
8 \\
0 \\
\end{array}$ & $\begin{array}{l}5 \\
0 \\
0 \\
8 \\
0 \\
0\end{array}$ & $\begin{array}{l}5 \\
0 \\
0 \\
8 \\
0 \\
0\end{array}$ & $\begin{array}{l}5 \\
0 \\
0 \\
8 \\
0\end{array}$ & & $\begin{array}{l}5 \\
0 \\
0 \\
0 \\
0\end{array}$ & & $\begin{array}{l} \pm \\
0 \\
0 \\
8 \\
\text { in }\end{array}$ & \\
\hline & & $\bar{c}^{\overline{0}} \cdot \Xi$ & 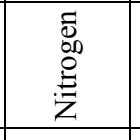 & 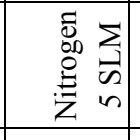 & 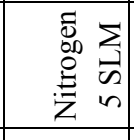 & 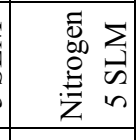 & 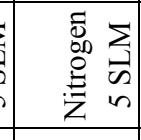 & 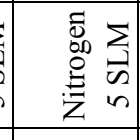 & 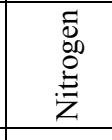 & $\begin{array}{l}\sum_{n} \\
n \\
i n\end{array}$ & 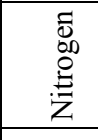 & $\begin{array}{l}\sum \\
\overrightarrow{5} \\
n \\
n\end{array}$ & 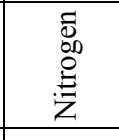 & \\
\hline & & 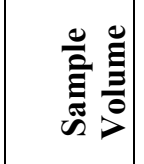 & $\begin{array}{l}\text { E } \\
\text { ¿ }\end{array}$ & & $\begin{array}{l}\infty \\
n \\
\tilde{b}\end{array}$ & $\begin{array}{l}0^{\infty} \\
8 \\
0\end{array}$ & 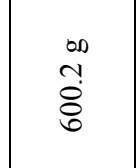 & $\begin{array}{l}\text { on } \\
\\
\tilde{8} \\
8\end{array}$ & $\begin{array}{l}\overline{0} \\
\text { on } \\
0 \\
\text { bे } \\
\text { in }\end{array}$ & 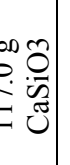 & $\begin{array}{l}\overline{0} \\
\text { bo } \\
\\
\alpha \\
\dot{y}\end{array}$ & 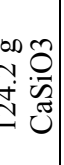 & 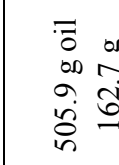 & $\begin{array}{ll}\infty & 0 \\
0 & 0 \\
0 & 0 \\
0 & 0 \\
0 & 0 \\
0\end{array}$ \\
\hline & & 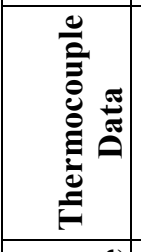 & & & 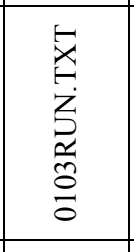 & 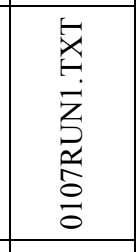 & 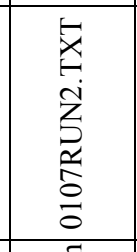 & 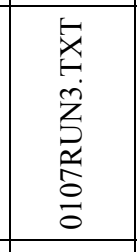 & 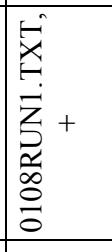 & 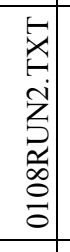 & 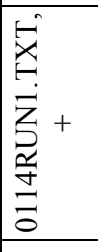 & 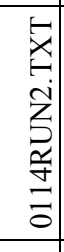 & 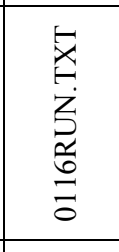 & \\
\hline & : & $\stackrel{\mathscr{I}}{\mathrm{I}}$ & & & $\begin{array}{l}\stackrel{a}{2} \cdot \\
\text { ?. }\end{array}$ & 吕 & 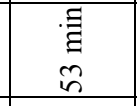 & ìn & $\frac{0}{i} \cdot \frac{\Xi}{z}$ & & 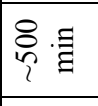 & & 号青 & \\
\hline & 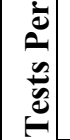 & 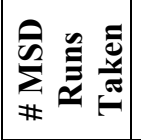 & & & 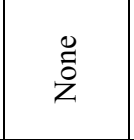 & 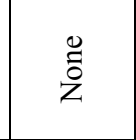 & 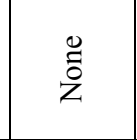 & $\stackrel{\ddot{0}}{z}$ & 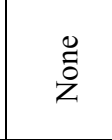 & & $\stackrel{0}{\tilde{z}}$ & & $\stackrel{\ddot{\Xi}}{z}$ & \\
\hline 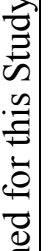 & 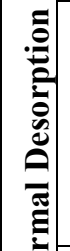 & 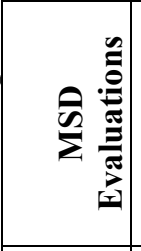 & & & $\begin{array}{l}\text { I } \\
\text { Z }\end{array}$ & $\stackrel{\circ}{z}$ & $\stackrel{\circ}{z}$ & $\stackrel{\circ}{z}$ & $\stackrel{\circ}{z}$ & & $\stackrel{\circ}{z}$ & & $\stackrel{\circ}{z}$ & \\
\hline$\frac{0}{0}$ & $\stackrel{8}{E}$ & ప & $\begin{array}{l}0 \\
8 \\
0\end{array}$ & $\begin{array}{l}0 \\
8\end{array}$ & $\begin{array}{l}0 \\
\stackrel{0}{0} \\
\text { in }\end{array}$ & Uి & نे & Uి & Uి & & ن & & $\begin{array}{l}0 \\
\stackrel{\text { ¿े }}{ }\end{array}$ & \\
\hline 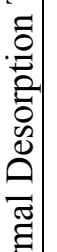 & & 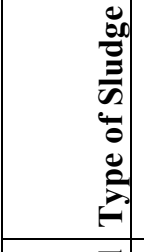 & 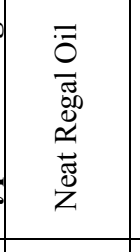 & 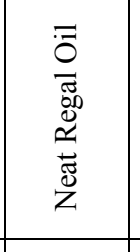 & 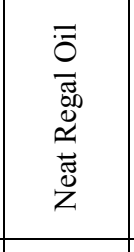 & 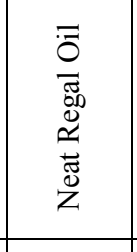 & 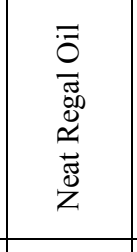 & 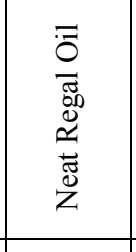 & 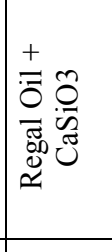 & & 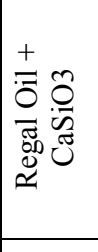 & & 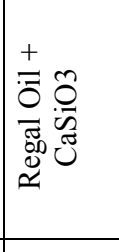 & \\
\hline $\begin{array}{l}\overline{5} \\
\\
\\
4 \\
0 \\
0 \\
0\end{array}$ & & 密 & 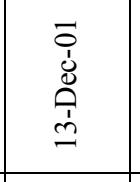 & $\begin{array}{l}\overline{0} \\
1 \\
0 \\
1 \\
\text { I }\end{array}$ & 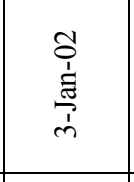 & $\begin{array}{l}\text { Õ } \\
i \\
\frac{1}{\pi} \\
i \\
i\end{array}$ & 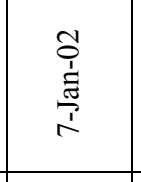 & 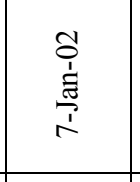 & 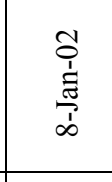 & & 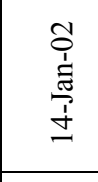 & & 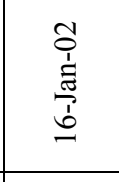 & \\
\hline$\stackrel{\Xi}{\Xi}$ & & 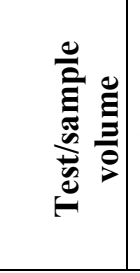 & 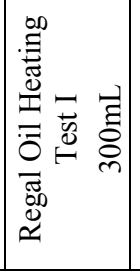 & 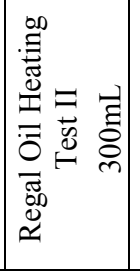 & 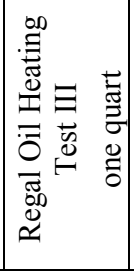 & 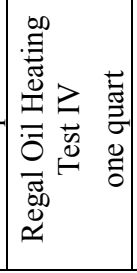 & 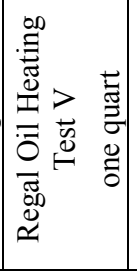 & 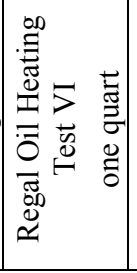 & 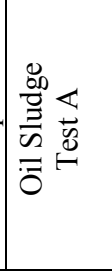 & $\begin{array}{l}\bar{\Xi} \\
\bar{\Xi} \\
0 \\
\Xi\end{array}$ & 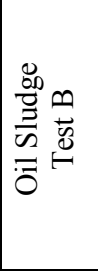 & $\begin{array}{l}\vec{t} \\
\vec{z} \\
\tilde{z} \\
\tilde{0}\end{array}$ & 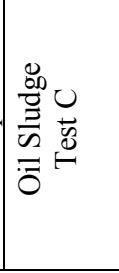 & $\begin{array}{l} \pm \\
\bar{t} \\
\bar{\Xi} \\
0 \\
0\end{array}$ \\
\hline
\end{tabular}




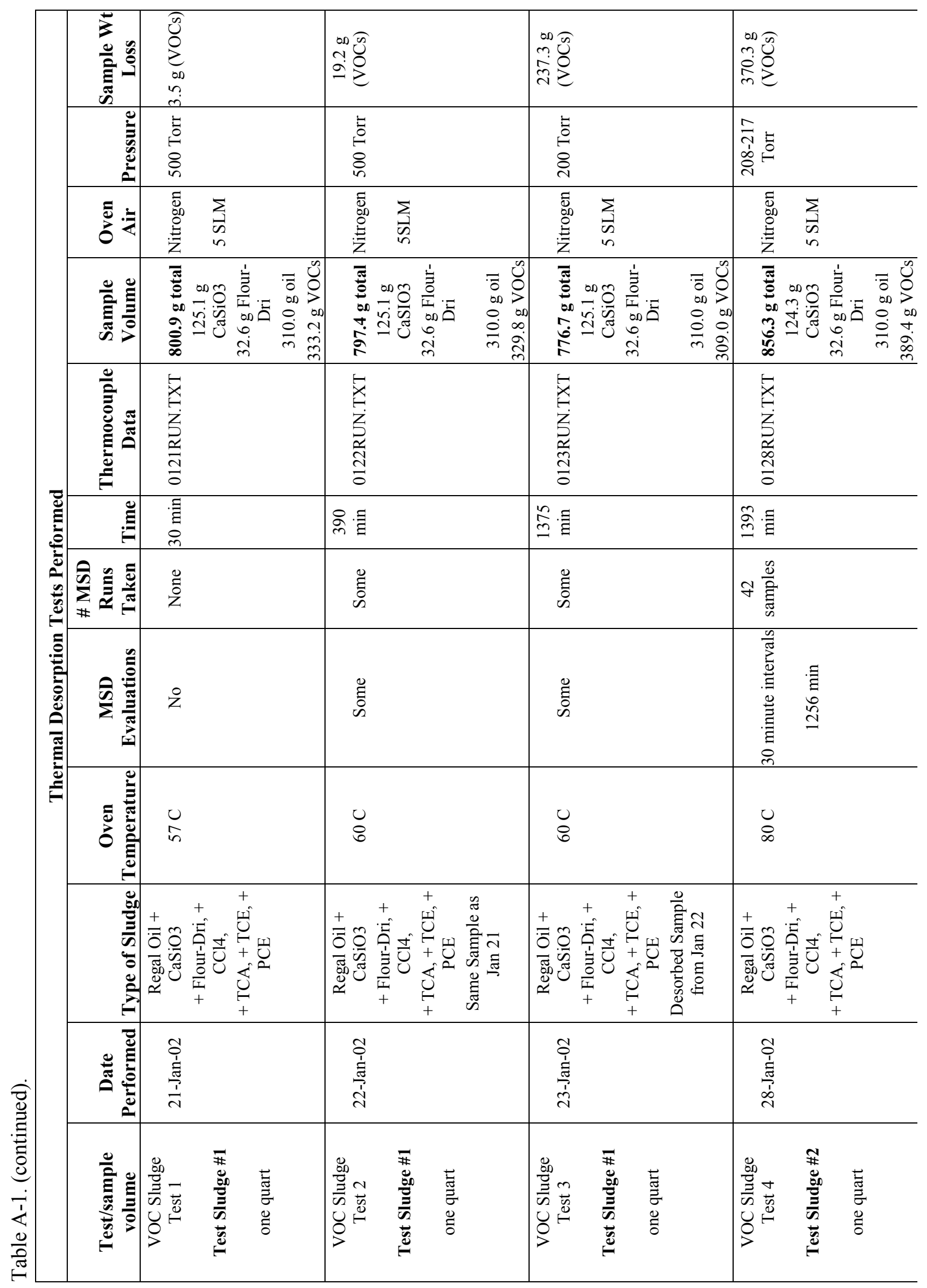




\begin{tabular}{|c|c|c|c|c|c|}
\hline & 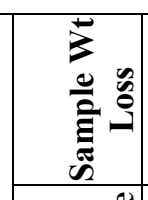 & 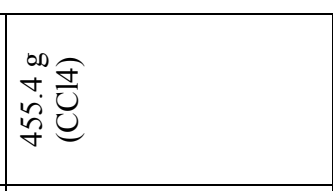 & 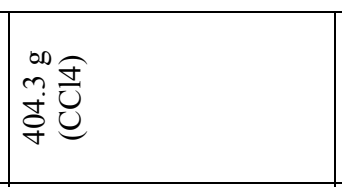 & 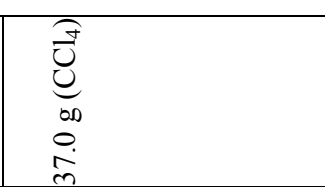 & 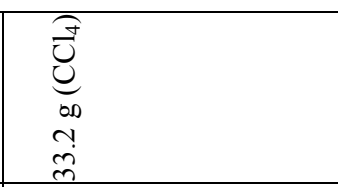 \\
\hline & 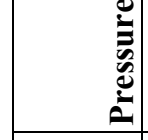 & 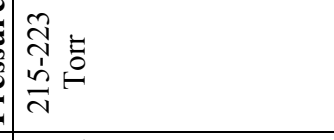 & 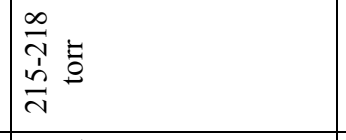 & $\begin{array}{l}5 \\
0 \\
0 \\
0\end{array}$ & 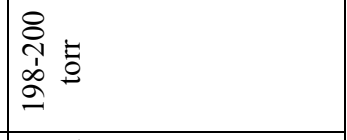 \\
\hline & $\overline{0}:=$ & 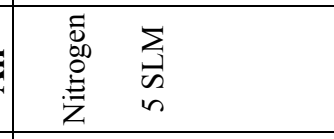 & 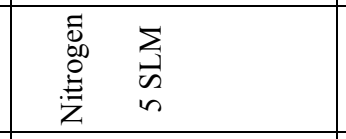 & 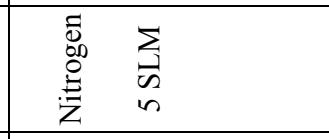 & 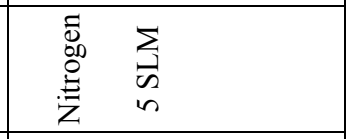 \\
\hline & 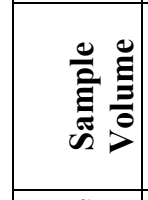 & 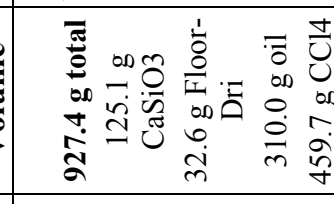 & 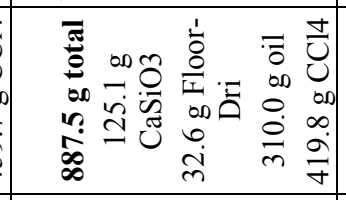 & 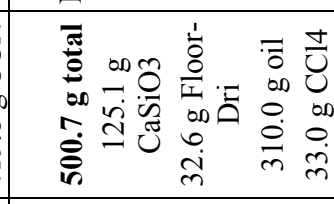 & 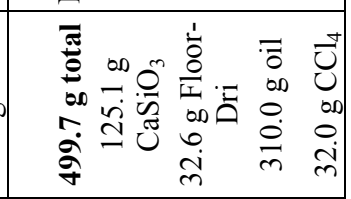 \\
\hline & 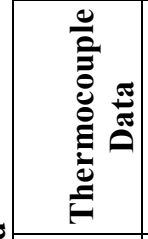 & 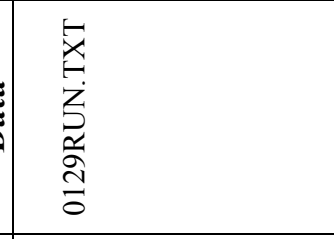 & 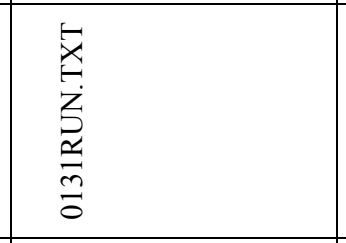 & 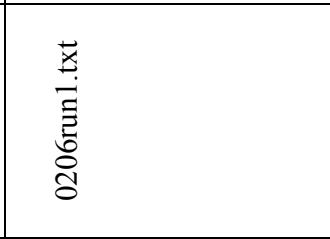 & 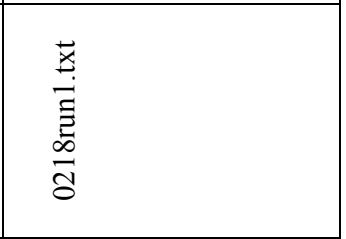 \\
\hline & : & 羔百 & 号慁 & 合夆 & $\stackrel{ }{\mathrm{I}} \cdot \dot{\mathrm{B}}$ \\
\hline & 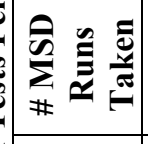 & 零 & 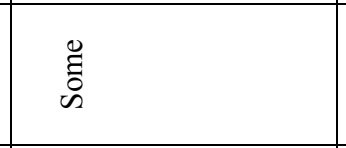 & ¿ & ๙ \\
\hline & $\sum \frac{a}{0}$ & 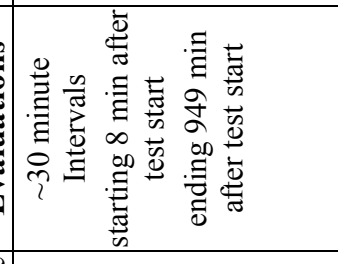 & 总 & 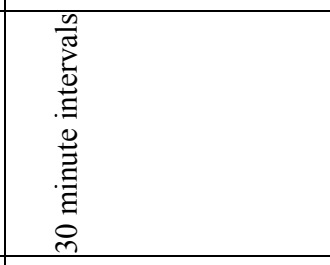 & 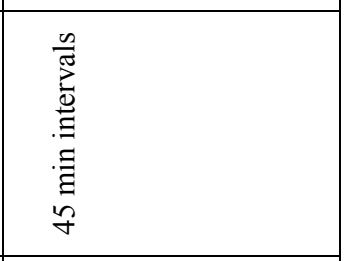 \\
\hline & 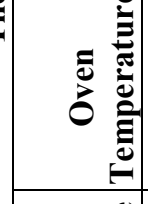 & $\begin{array}{l}0 \\
\infty \\
\infty\end{array}$ & $\begin{array}{l}0 \\
\infty\end{array}$ & $\begin{array}{l}0 \\
\infty \\
\infty\end{array}$ & $\begin{array}{l}0 \\
\infty\end{array}$ \\
\hline & 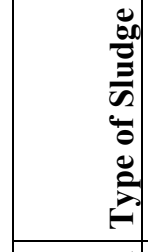 & 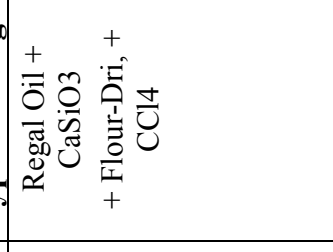 & 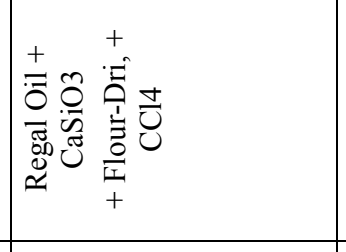 & 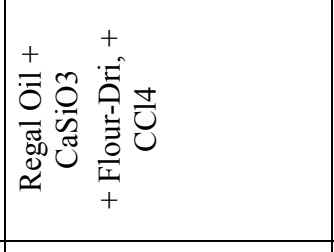 & 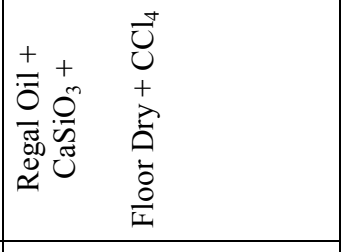 \\
\hline & जิ & 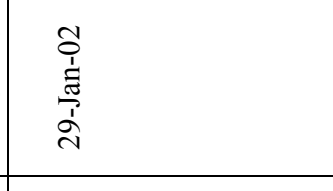 & 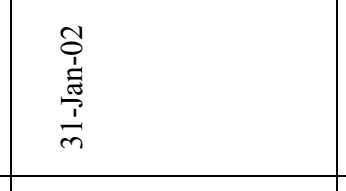 & $\begin{array}{l}\text { Co } \\
\frac{1}{0} \\
\frac{0}{0} \\
\frac{1}{6}\end{array}$ & 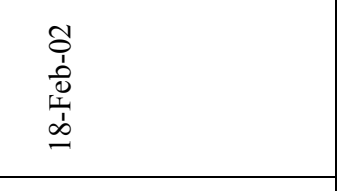 \\
\hline & 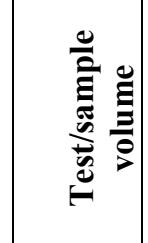 & 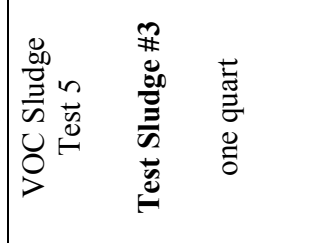 & 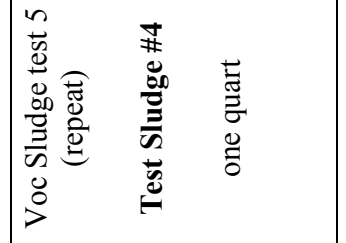 & 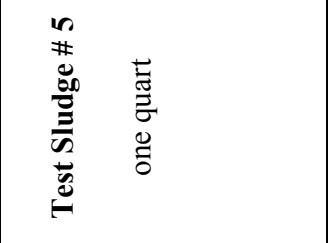 & 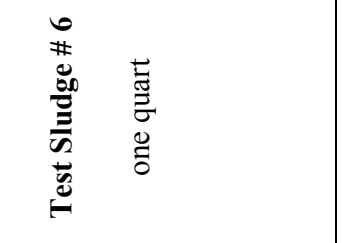 \\
\hline
\end{tabular}




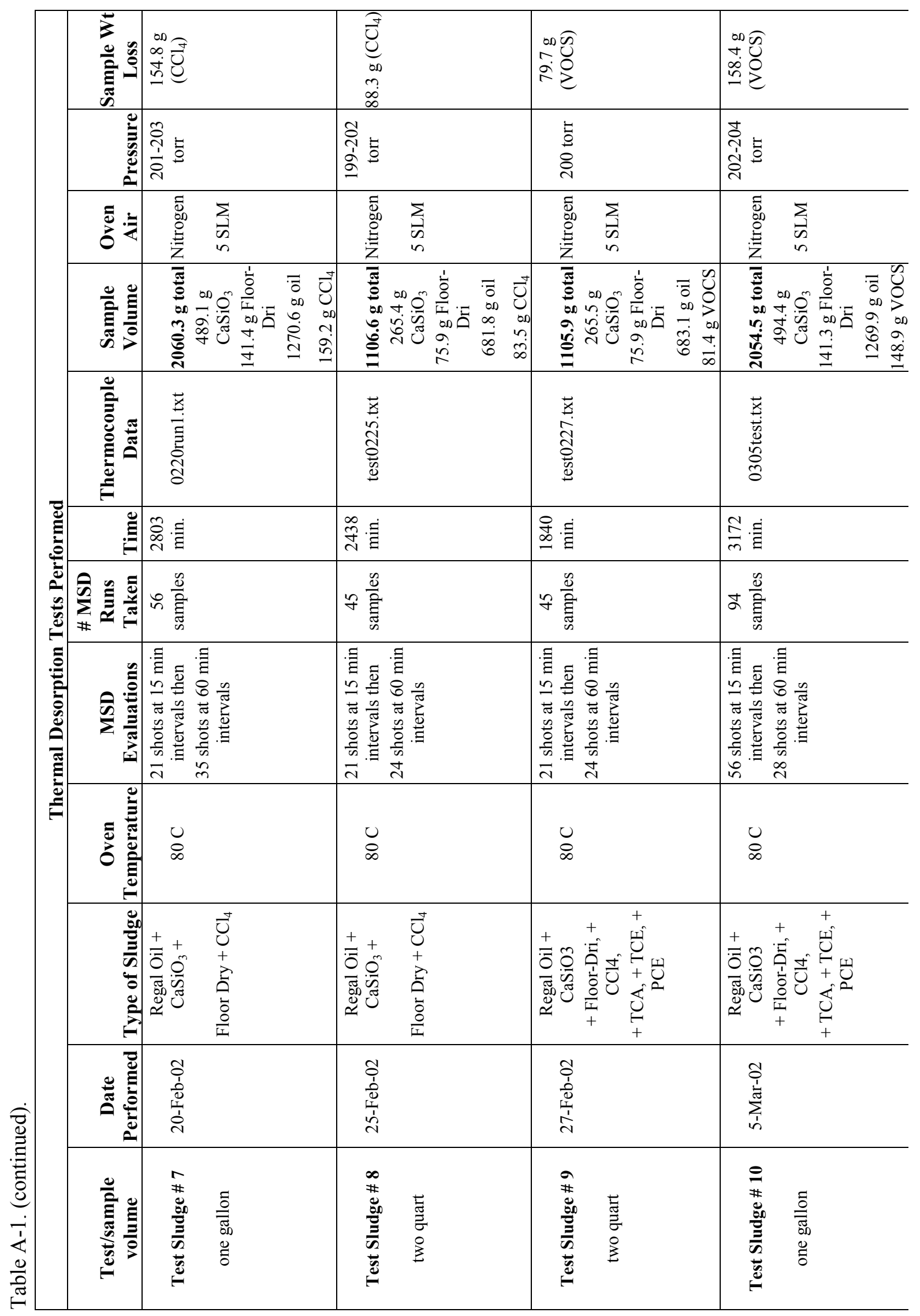




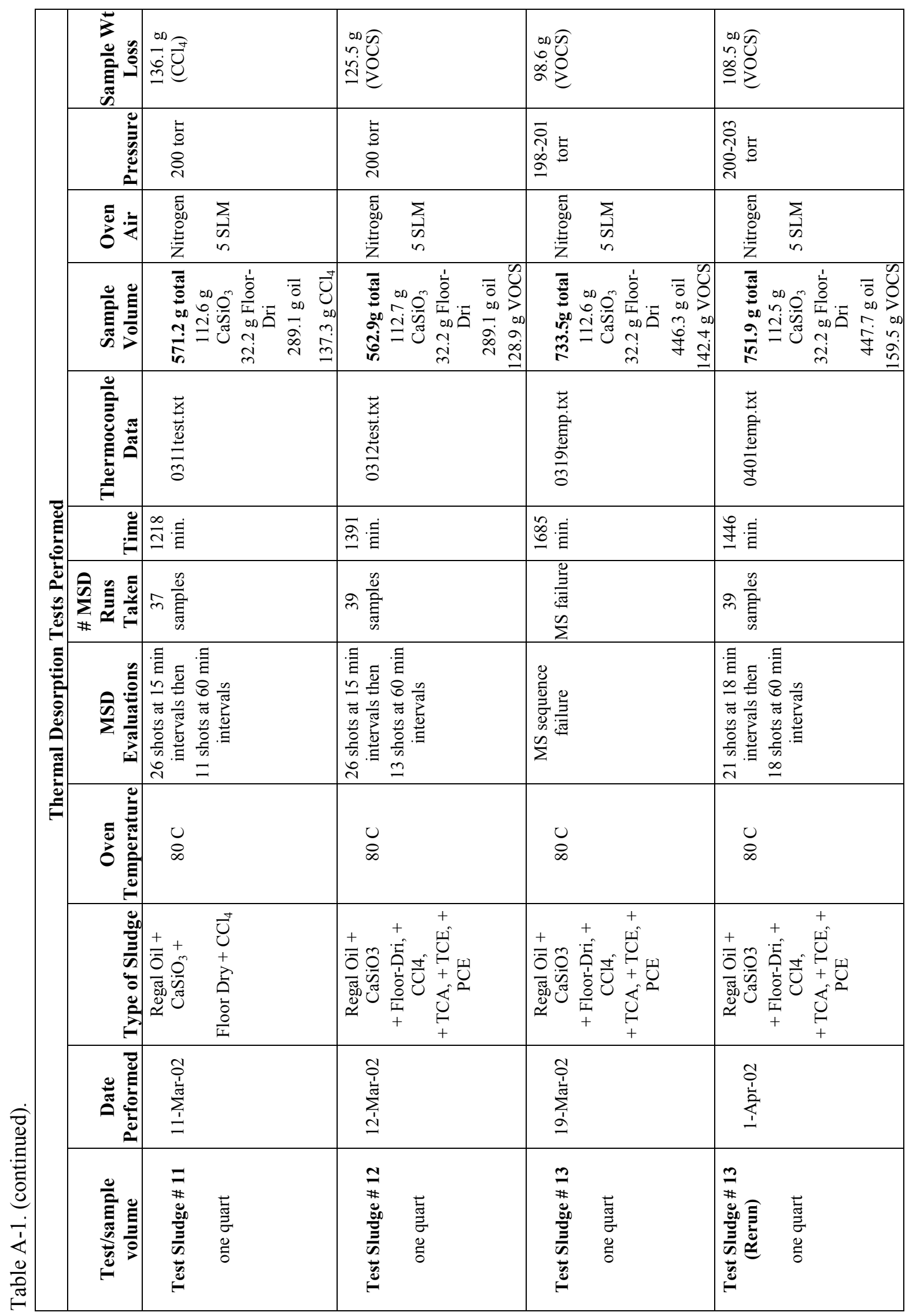




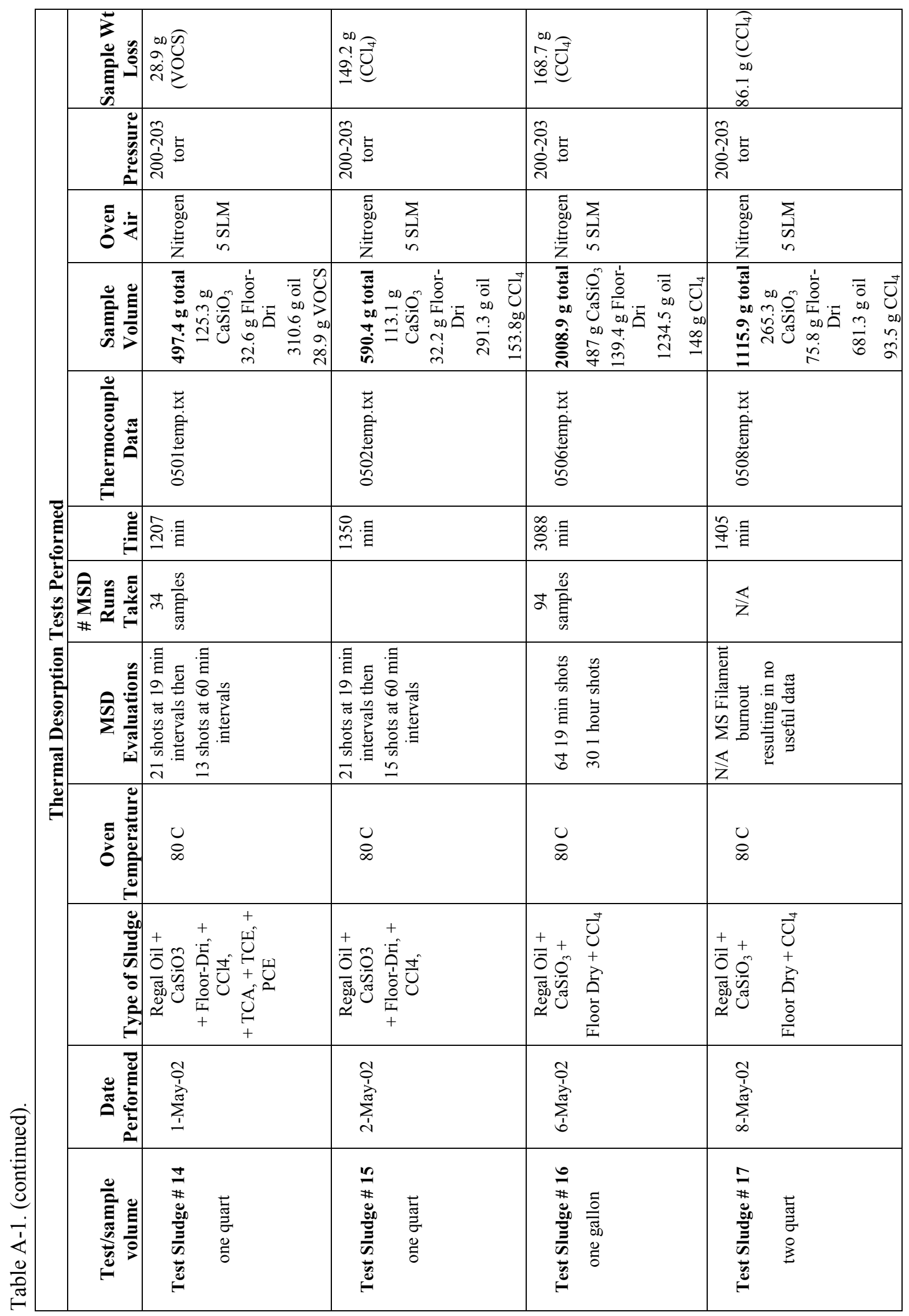




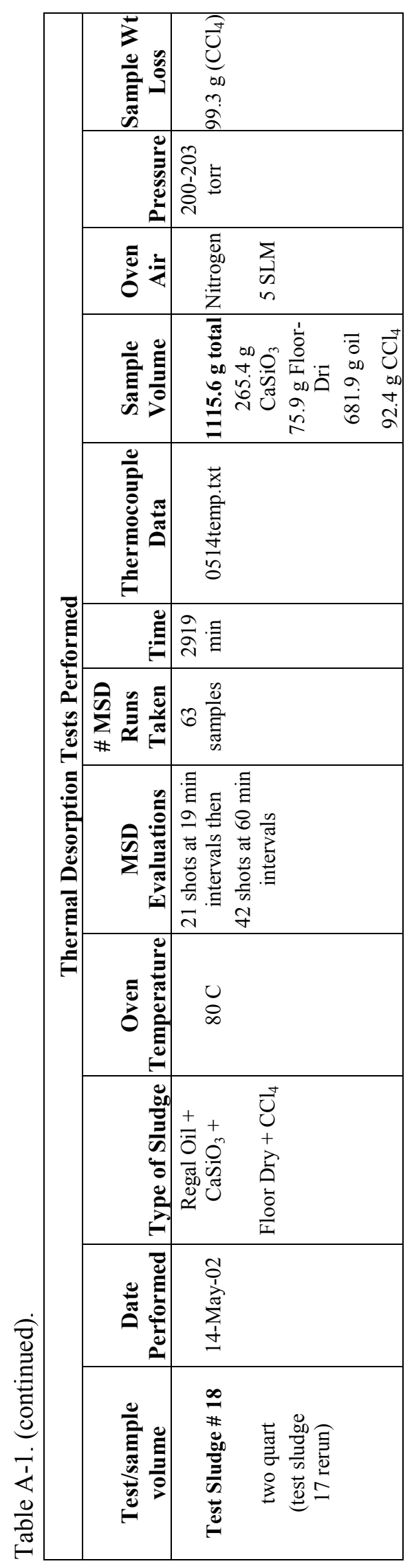




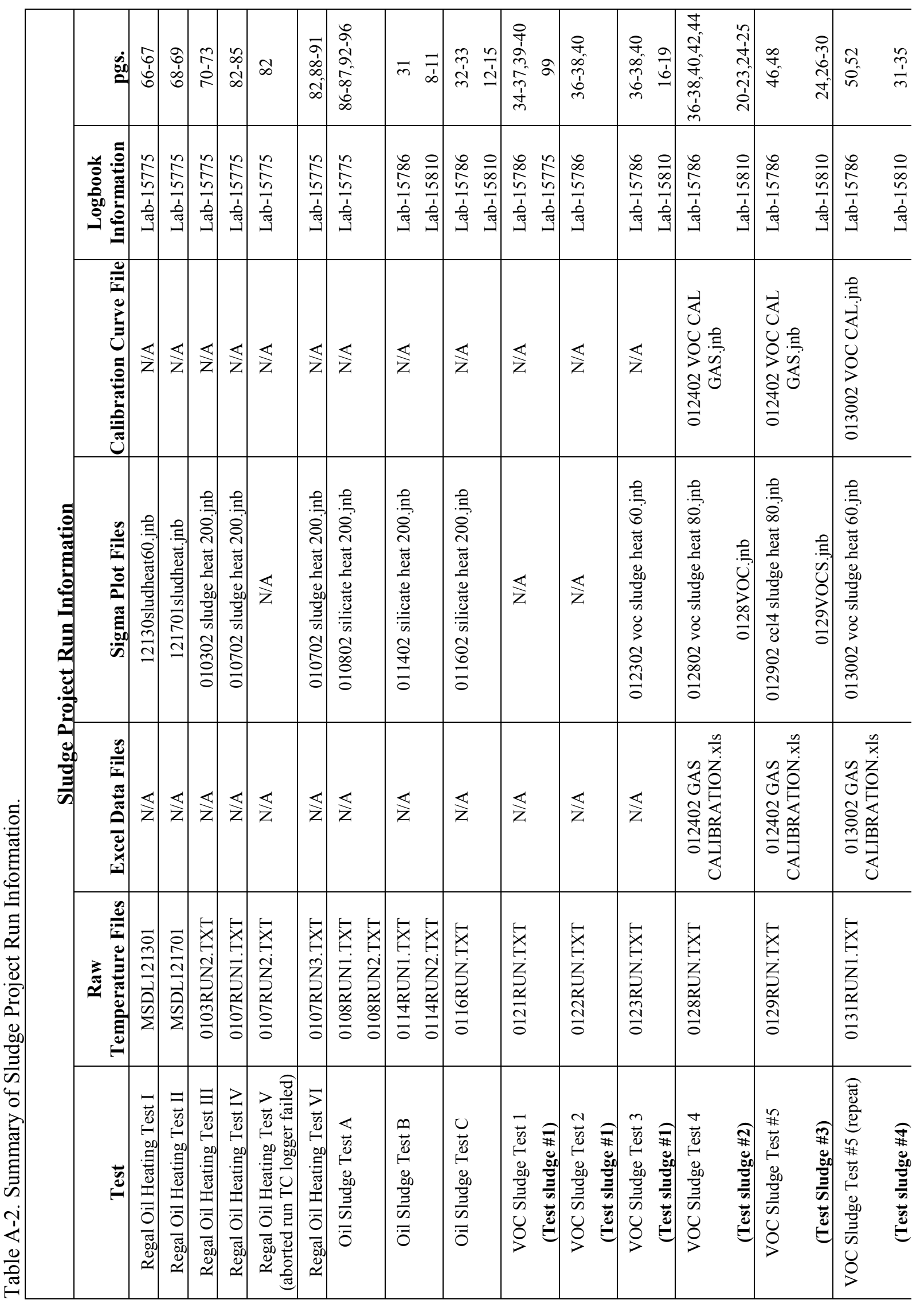




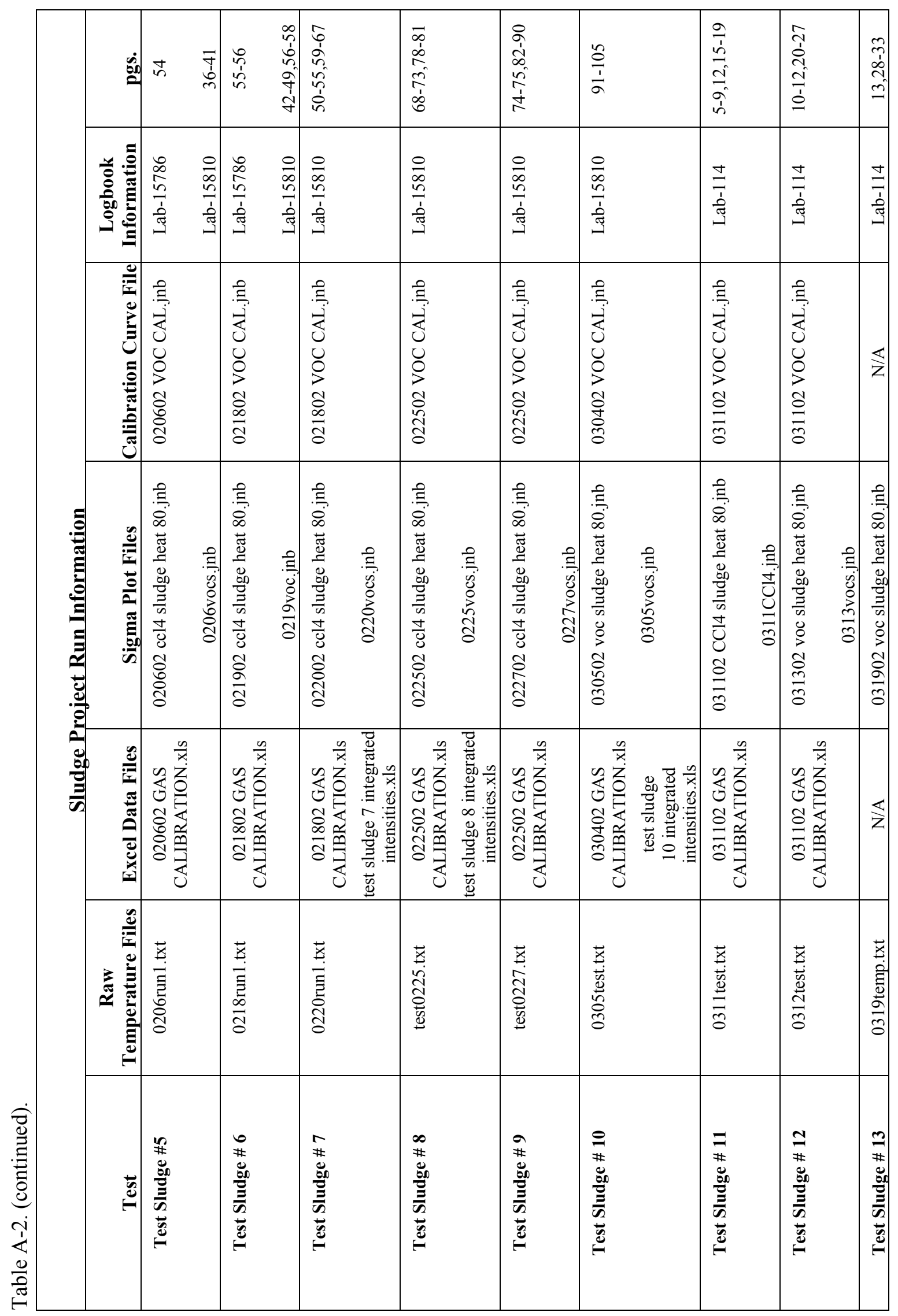




\begin{tabular}{|c|c|c|c|c|c|c|c|c|}
\hline & & 吕 & 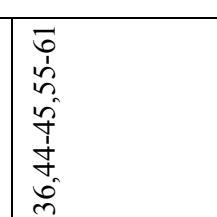 & $\begin{array}{l}n \\
\vdots \\
\vdots \\
0 \\
\tilde{y} \\
\dot{y} \\
\dot{y}\end{array}$ & 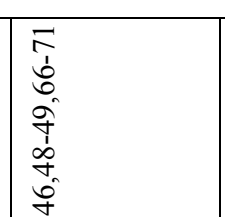 & $\begin{array}{l}\text { D } \\
\hat{i} \\
\hat{i} \\
\hat{n} \\
i\end{array}$ & 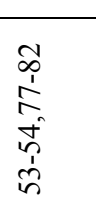 & \\
\hline & 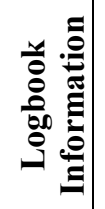 & 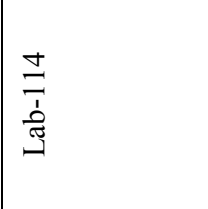 & $\begin{array}{l}\underset{7}{ \pm} \\
\stackrel{\vec{J}}{\Xi}\end{array}$ & $\begin{array}{l}\underset{J}{ \pm} \\
\underset{\Xi}{ \pm}\end{array}$ & $\begin{array}{l}\underset{J}{ \pm} \\
\underset{\Xi}{ \pm}\end{array}$ & 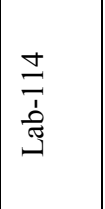 & 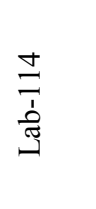 & \\
\hline & 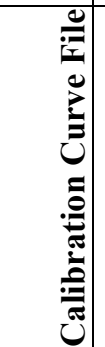 & 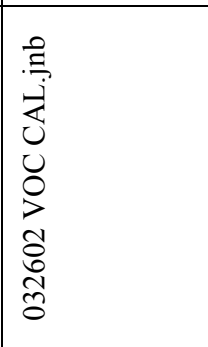 & 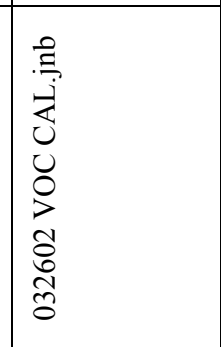 & 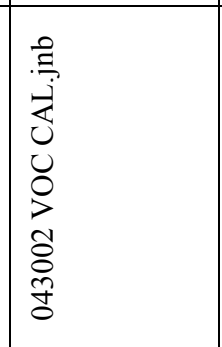 & 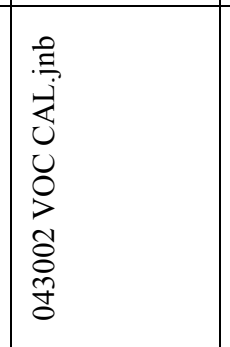 & $\overleftrightarrow{z}$ & 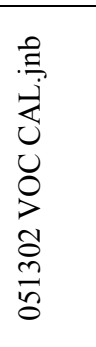 & \\
\hline 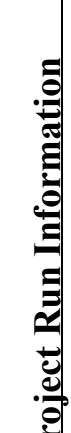 & 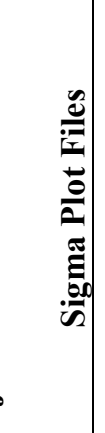 & 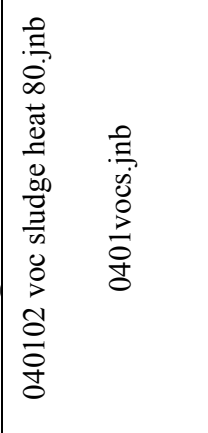 & 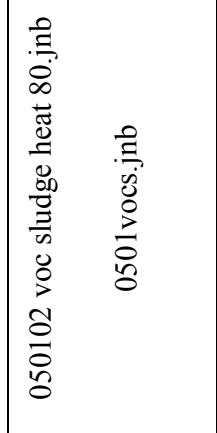 & 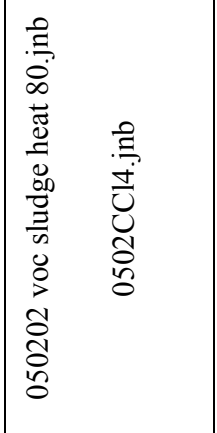 & 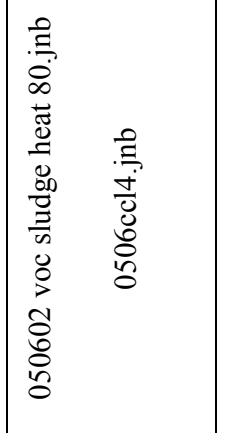 & 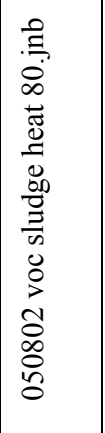 & 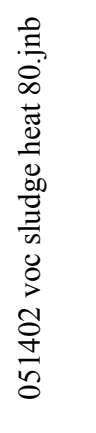 & 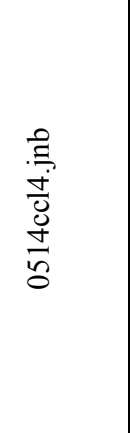 \\
\hline$\frac{\overrightarrow{0}}{0}$ & 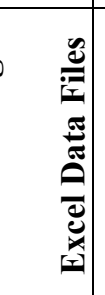 & 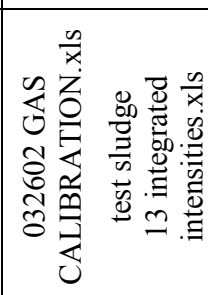 & 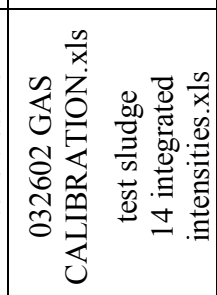 & 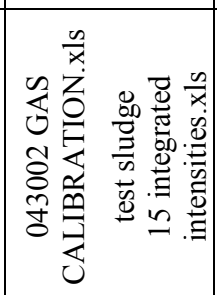 & 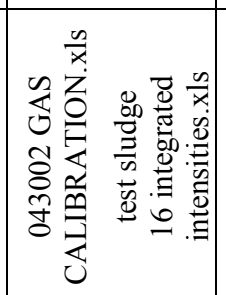 & $\overleftrightarrow{z}$ & 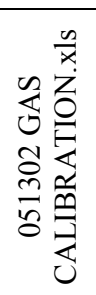 & 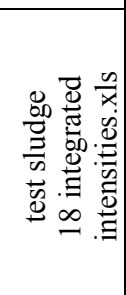 \\
\hline & | & 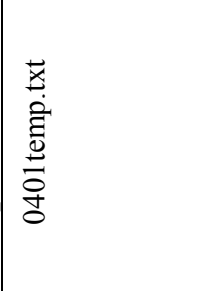 & $\begin{array}{l}\vec{x} \\
\dot{\vec{a}} \\
\dot{\vec{g}} \\
\stackrel{0}{0} \\
\stackrel{0}{0}\end{array}$ & 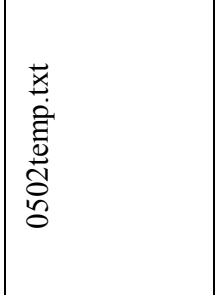 & 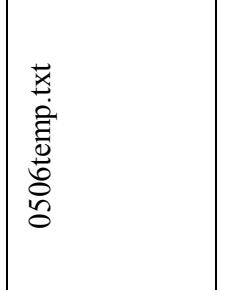 & 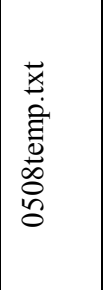 & 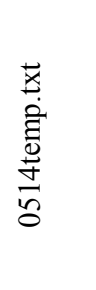 & \\
\hline & $\stackrel{5}{a}$ & 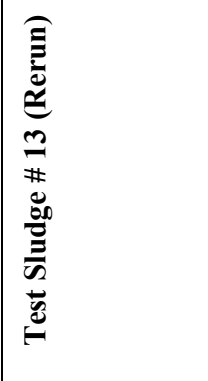 & 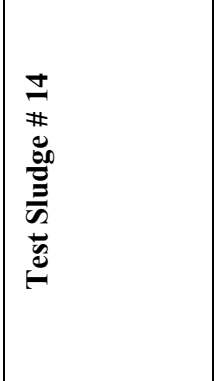 & 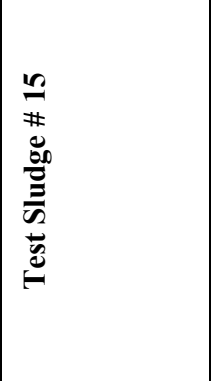 & 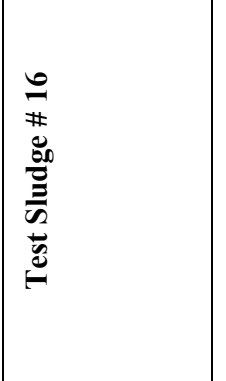 & 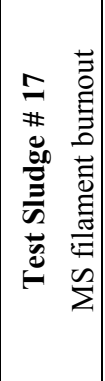 & 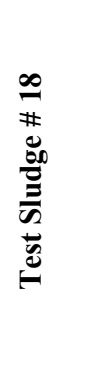 & 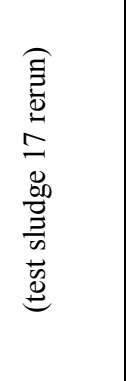 \\
\hline
\end{tabular}

